\title{
Microstructure dynamics of rechargeable battery materials studied by advanced transmission electron microscopy
}

\begin{abstract}
Yuren Wen ${ }^{1}$, Dongdong Xiao ${ }^{1}$, Xiaozhi Liu ${ }^{1,3}$ and Lin $\mathrm{Gu}^{1,2,3}$
The ever-growing energy requirements, the decreasing fossil fuel resources and the urgent need for environmental protection have spurred the search for sustainable energy alternatives, including both renewable energy sources and efficient storage technologies. Lithium/sodium (Li/Na)-ion batteries (LIBs/SIBs) are the most attractive and promising energy storage devices in the consumer market. The primary progress made by using advanced transmission electron microscopy (TEM) characterization and its close correlation with the battery properties are reviewed here. In addition, the atomic structure and chemistry of electrode materials are illustrated with respect to the surface reconstruction and the interface structure. The phase transformation and defect evolution are then discussed with respect to (1) the intermediate state of $\mathrm{LiFePO}_{4}$ that results in a high rate capability; (2) the in situ electrochemical reaction on nanomaterials; and (3) the alloying reaction for the high-energydensity silicon ( $\mathrm{Si}$ ) anode. The fundamental science underlying the microstructure evolution has been explored in depth to the atomic level and is discussed further in the context of electronic structure theory.
\end{abstract}

NPG Asia Materials (2017) 9, e360; doi:10.1038/am.2017.19; published online 10 March 2017

\section{INTRODUCTION}

There is an urgent need to build a sustainable society by developing clean energy technologies to replace fossil fuels. ${ }^{1}$ In this respect, energy conversion and storage devices are highly desirable because they can shift the electric energy from peak to off-peak periods, thus resulting in efficient energy use. Rechargeable batteries, one of the most important energy storage devices, have evolved over the past years from lead acid through nickel-cadmium and nickel-metal hydride to lithium (Li)-ion batteries. Rechargeable batteries will be replaced by higher energy, lighter weight and lower cost Li-ion batteries (LIBs) in fields such as hybrid electric vehicles. ${ }^{2,3}$ Compared with LIBs, sodium (Na)-ion batteries (NIBs) are more cost effective, use a much more earth-abundant and environmental friendly metal $\mathrm{Na}$ and are suitable for stationary grid storage applications. ${ }^{4}$ LIBs/SIBs have various applications (such as portable electronics, transportation and load leveling) owing to their high volumetric and gravimetric energy densities.

The performance of rechargeable batteries (that is, their energy density, capacity fade, rate capability and cycling life) is critically dependent on their electrode materials. ${ }^{5}$ A number of characterization techniques have been used to investigate these electrode materials. For example, synchrotron X-rays provide a bright signal allowing study of the microstructure evolution on a global scale during charging/ discharging. In contrast, fast electrons with a small wavelength are used to image and characterize the material structure at a high resolution. By collecting the inelastically scattered electrons after the interaction of the electrons with transparent thin foils, the chemical composition and electronic structure of the material can be determined. Transmission electron microscopy (TEM), particularly after the introduction of aberration correctors, has evolved into a powerful tool for studying the crystal structure, chemical composition and electronic structure at atomic resolution. ${ }^{6-8}$

A rechargeable battery can be considered as a live and functional system. The battery performance depends on the components of the individual materials, the interface engineering and the system optimization. ${ }^{9}$ The design of better batteries requires an in-depth understanding of the relationship between properties and structure, especially that of the electrode materials at operation conditions. ${ }^{10}$ Thus, in situ TEM is one of the most powerful tools to investigate the microstructure evolution that determines the battery performance. ${ }^{11}$

\section{INTERFACE STRUCTURE}

The practical implementation of some layered cathode materials is hindered by their high first-cycle Coulombic inefficiency, capacity fading and voltage instability, especially during high voltage operation. Specifically, these functional failures in cathode materials are directly associated with various irreversible electrochemical processes including $\mathrm{O}$ loss, concomitant $\mathrm{Li}$-ion removal and side reactions at the solid-electrolyte interface. ${ }^{12}$ A schematic of the layered-to-spinel transformation after charging can be found elsewhere. ${ }^{13}$ Extensive structural studies on $\mathrm{Li}-\mathrm{Mn}$-rich cathode materials have shown a

${ }^{1}$ Beijing National Laboratory for Condensed Matter Physics, Institute of Physics, Chinese Academy of Sciences, Beijing, China; ${ }^{2}$ Collaborative Innovation Center of Quantum Matter, Beijing, China and ${ }^{3}$ School of Physical Sciences, University of Chinese Academy of Sciences, Beijing, China Correspondence: Professor L Gu, Institute of Physics, Chinese Academy of Sciences, No. 8, 3rd South Street, Zhongguancun, Haidian District, Beijing 100190, China. E-mail: I.gu@iphy.ac.cn 

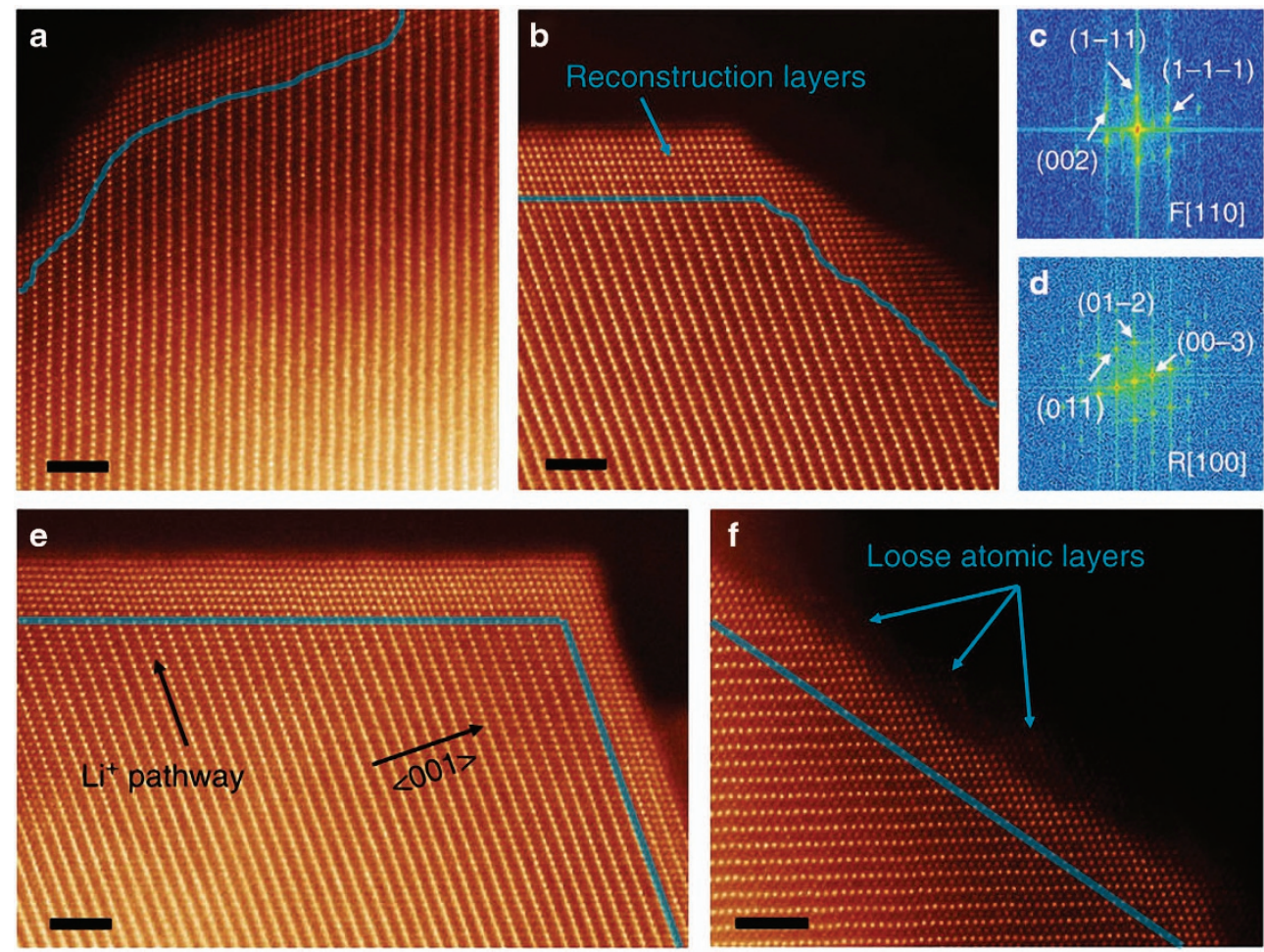

Figure 1 Atomic-scale resolution annular dark-field scanning transmission electron microscopy (ADF-STEM) images of $\mathrm{LiNi}_{0.4} \mathrm{Mn}_{0.4} \mathrm{Co}_{0.18} \mathrm{Ti}_{0.02} \mathrm{O}_{2}$ ( $\mathrm{NMC}$ ) particles. (a) After electrolyte exposure and (b) after one cycle, with the blue arrow indicating the surface reconstruction layer (SRL). (c, d) FFT patterns showing the surface reconstruction layer (Fm-3m [110] zone axis) and the NMC layered structure (R-3m [100] zone axis), respectively from (b). (e) Image showing the variation of the SRL thickness on the orientation after one cycle. (f) Image showing loose atomic layers on an NMC particle after one cycle. In all the images, the blue lines indicate the boundaries between the NMC layered structure and SRL. In all the images, the scale bars are 2 nm. Reproduced with permission. 15

phase transformation from a layered structure (involving an initial phase change from a $\mathrm{C} 2 / \mathrm{m}$ to a hexagonal $\mathrm{R}-3 \mathrm{~m}$ phase after activation) to a spinel-like structure (Fd-3m space group) and finally to a disordered rock-salt structure (Fm-3m space group), as the electrochemical cycling progresses. ${ }^{14}$

As shown in Figure 1, pristine $\mathrm{LiNi}_{0.4} \mathrm{Mn}_{0.4} \mathrm{Co}_{0.18} \mathrm{Ti}_{0.02} \mathrm{O}_{2}$ (NMC) powders exhibit a surface reconstruction layer after electrolyte exposure (Figure 1a) and after one cycle (Figure 1b). Fast Fourier transform (FFT) results show a transition from a layered NMC $(\mathrm{R}-3 \mathrm{~m})$ phase to a rock-salt $(\mathrm{Fm}-3 \mathrm{~m})$ structure. These observations provide new insights into the origin of the capacity degradation and the impedance buildup in NMC materials under high voltage cycling conditions. In addition, the structural reconstruction at the surface is anisotropic, and it primarily occurs along the Li-ion transport direction (Figure 1e). This finding suggests that the surface reconstruction is promoted by Li removal during charging, with a more severe reconstruction in the regions undergoing dynamic Li transport. Interestingly, loose atomic layers from the cubic rock-salt structure (indicated by blue arrows in Figure 1f) have also been observed at the external surface of the reconstruction layers. ${ }^{15}$ These loosely attached atomic layers are susceptible to dissolution into the electrolytes, thus potentially explaining the suspected $\mathrm{Mn}^{2+}$ dissolution in a variety of Mn-containing cathodes. ${ }^{16} Z$-contrast high-resolution scanning transmission electron microscopy (STEM) also has provided evidence of the migration of surface transition-metal (TM) ions into the Li layer, thereby possibly affecting the TM-O bonding characteristics, as indicated by the electron energy loss spectroscopy (EELS) results. Moreover, a noticeable reduction in the Li signal has been observed in the EELS spectrum of the surface area (versus that of the bulk), a finding consistent with the observation that significant TM atoms occupy $\mathrm{Li}$ sites on the cycled surface. ${ }^{17,18}$ A detailed explanation of the electronic origin in the migration of TM ions and surface reconstruction can be found in the 'TM cation migration and TM-O coordination' section.

The interface is an intrinsic property that determines the ion and electron transport phenomena in battery materials. ${ }^{19-22}$ Microstructural characterization at the grain and phase interfaces has provided significant insight into the electrochemical transformation and the ion/electron conduction.

A three-phase separation mechanism has been proposed by Sun et al. ${ }^{23}$ during sodiation of a spinel $\mathrm{Li}_{4} \mathrm{Ti}_{5} \mathrm{O}_{12}$ electrode. In this case, a [110] projection is most suitable for observation because separated columns of $\mathrm{Li}, \mathrm{O}$ and $\mathrm{Ti}$ ions are aligned in this direction (Figure 2a). Because $\mathrm{Li}_{4} \mathrm{Ti}_{5} \mathrm{O}_{12}$ and $\mathrm{Li}_{7} \mathrm{Ti}_{5} \mathrm{O}_{12}$ share an almost identical $\left[\mathrm{Ti}_{5} \mathrm{Li}\right]^{16 \mathrm{~d}} \mathrm{O}_{12}$ host, they are nearly indistinguishable in high-angle annular dark-field (HAADF) images, because of the lack of contrast between the Li columns (Figures $2 \mathrm{~b}$ and e). However, in annular bright-field $(\mathrm{ABF})$ images, the contrast between the Li-ions can be identified at the $8 \mathrm{a}$ (Figure 2c) and $16 \mathrm{c}$ sites (Figure 2f) for $\mathrm{Li}_{4} \mathrm{Ti}_{5} \mathrm{O}_{12}$ and $\mathrm{Li}_{7} \mathrm{Ti}_{5} \mathrm{O}_{12}$, respectively. The corresponding line profiles provide a much clearer picture of the position of Li-ions (Figures $2 \mathrm{~d}$ and $\mathrm{g}$ ). The HAADF images of the sodiated $\mathrm{Li}_{4} \mathrm{Ti}_{5} \mathrm{O}_{12}$ reveal a significant contrast at the $16 \mathrm{c}$ site (Figure $2 \mathrm{~h}$ ), that is distinguished from both the Li7 and Li4 phases. Thus, atoms with a large $Z$ emerge at the $16 \mathrm{c}$ sites after $\mathrm{Na}$ ion insertion, probably because of the formation of a Na6Li phase. The $\mathrm{ABF}$ images of the Na6Li phase (Figure 2i) reveal a contrast gap 
a
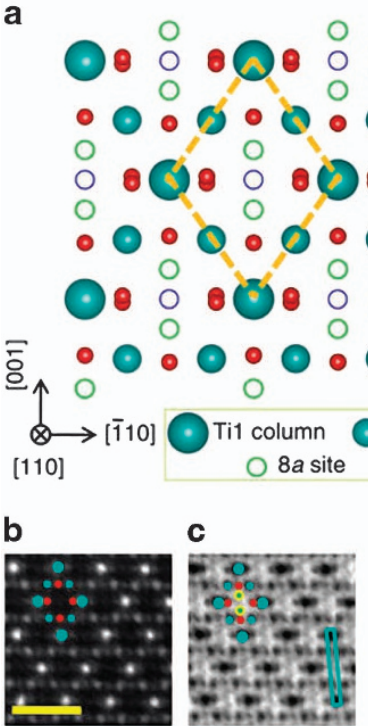

d

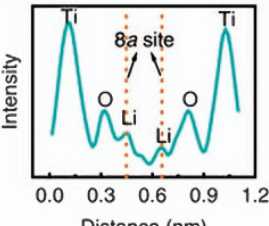

e

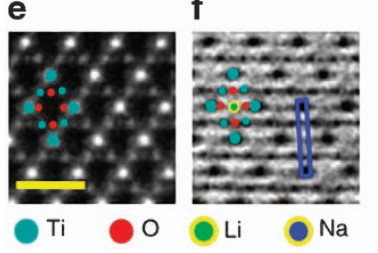

g

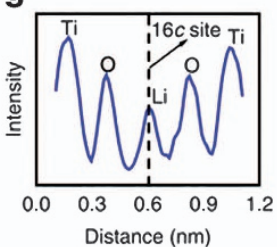

h

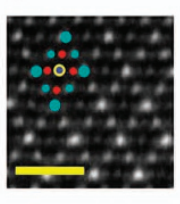

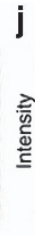

j

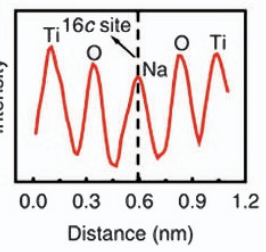

\section{k}

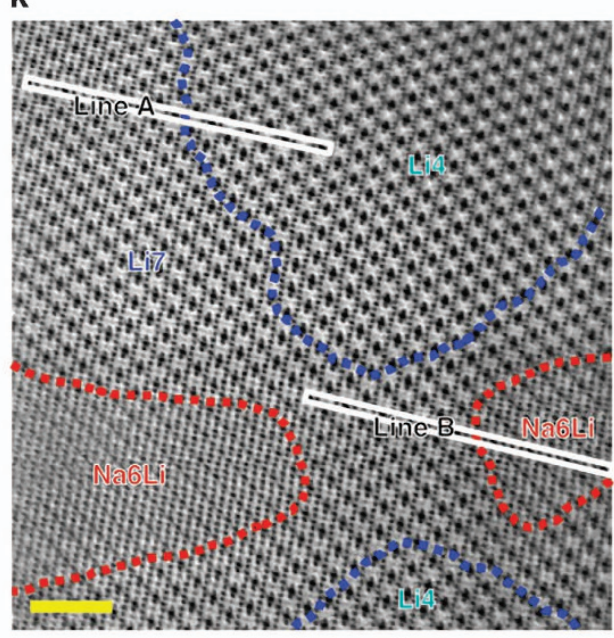

Li7/Li4 boundary Li7/Na6Li boundary

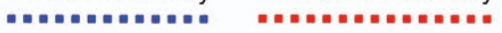

I

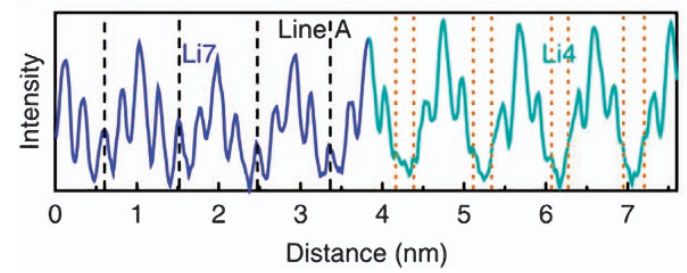

m

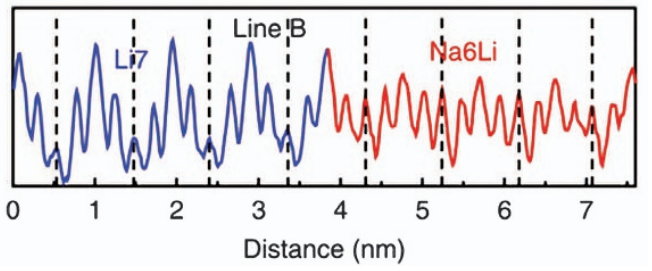

Figure 2 STEM images of a three-phase coexistence region. (a) Crystal structure of the spinel $\mathrm{Li}_{4} \mathrm{Ti}_{5} \mathrm{O}_{12}$ viewed from the [110] crystallographic direction, showing the separated $\mathrm{Ti}$ and $\mathrm{O}$ columns. Ti1 and Ti2 columns with different atom densities are represented by balls of different sizes. (b) HAADF and (c) ABF images and (d) $A B F$ line profile of the $\mathrm{Li}_{4} \mathrm{Ti}_{5} \mathrm{O}_{12}$ (Li4) phase. Scale bar is $1 \mathrm{~nm}$. (e) HAADF and (f) ABF images and (g) ABF line profile of the $\mathrm{Li}_{7} \mathrm{Ti}_{5} \mathrm{O}_{12}$ (Li7) phase. Scale bar is $1 \mathrm{~nm}$. (h) HAADF and (i) ABF images and (j) ABF line profile of $\mathrm{Na}_{6} \mathrm{LiTi}_{5} \mathrm{O}_{12}$ (Na6Li) phase. Scale bar is $1 \mathrm{~nm}$. (k) ABF image of the half-sodiated $\mathrm{Li}_{4} \mathrm{Ti}_{5} \mathrm{O}_{12}$ nanoparticle. In the ABF line profile, the contrast is inverted for a convenient visualization. Scale bar is $2 \mathrm{~nm}$. (I, $\mathbf{m}$ ) Line profiles that cross the Li7/Li4 (line A) and Li7/Na6Li (line B) boundaries, respectively. Reproduced with permission. ${ }^{23}$

between the different atomic columns that is significantly lower than that in the Li7 and Li4 phases, as shown in the line profile (Figure 2j). Accordingly, a three-phase coexistence region is found in halfdischarged samples (Figure 2k), with distinguishable Li7/Li4 and $\mathrm{Li} / \mathrm{Na} 6 \mathrm{Li}$ phase boundaries (Figures $2 \mathrm{l}$ and $\mathrm{m}$ ). The interface (at the atomic scale) for a phase transition reaction in an electrochemically inserted sample is clearly visible, thus closely reflecting the real behavior of the battery. The two-phase boundaries of Li7/Li4 and $\mathrm{Li} / \mathrm{Na} 6 \mathrm{Li}$ are sharp and show no dislocation (Figures $2 \mathrm{l}$ and $\mathrm{m}$ ), a result consistent with previous observations for a chemically lithiated $\mathrm{Li}_{4} \mathrm{Ti}_{5} \mathrm{O}_{12}$ phase. ${ }^{24}$

\section{PHASE TRANSFORMATION}

\section{Intermediate transition}

Olivine $\mathrm{LiFePO}_{4}$ has been used as a positive electrode in LIBs owing to its low cost and excellent safety features. Despite its insulating nature (an electronic conductivity of $10^{-9} \mathrm{~S} \mathrm{~cm}^{-1}$ ), the use of cation-doped small particles and carbon coating has achieved a full theoretical capacity and high power operation. ${ }^{19,25-29}$ Since the discovery of $\mathrm{LiFePO}{ }_{4}, 30$ its phase transformation and outstanding performance in high rate discharge/charge cycling applications have been under debate. ${ }^{31-34}$

Despite a number of intensive studies, the direct observation of the intermediate structure of $\mathrm{Li}_{\mathrm{x}} \mathrm{FePO}_{4}$ during phase transformation is lacking. Nishimura et al. $^{35}$ have demonstrated the presence of a long-range ordered metastable $\mathrm{Li}_{2 / 3} \mathrm{FePO}_{4}$ phase. A polaronic charge-ordered structure has been determined from the electron diffraction pattern (EDP) at room temperature. Figure 3 (top) depicts the EDP of a metastable mixed-valence-phase $\mathrm{Li}_{2 / 3} \mathrm{FePO}_{4}$ and shows a threefold long-range ordering along the $a$ axis. This superstructure provides an advanced level of understanding of the competitive ordering behavior of the Li/vacancy versus $\mathrm{Fe}^{+3} / \mathrm{Fe}^{2+}$. The final 

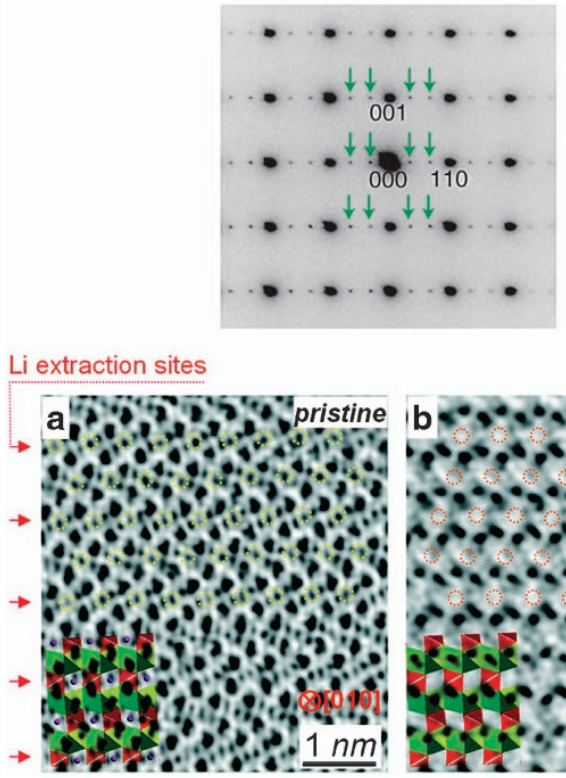

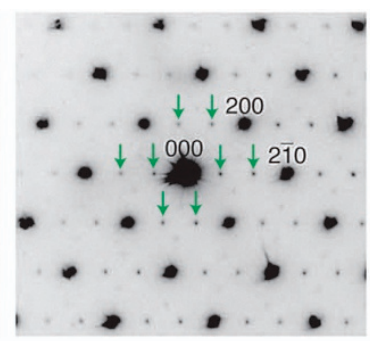

disordered Fe-P columns
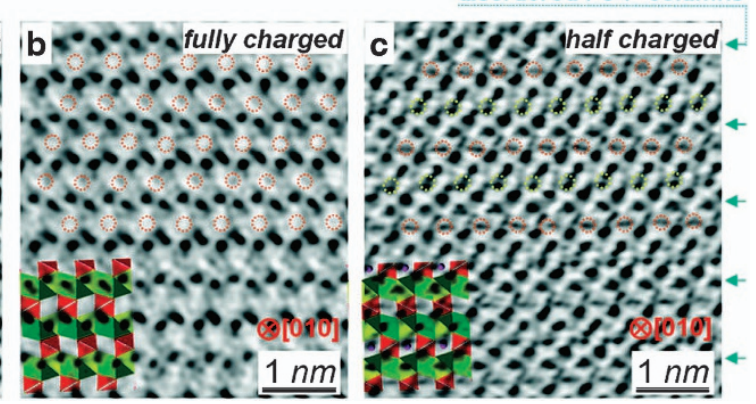

Figure 3 (Top). EDP of metastable mixed-valence-phase $\mathrm{Li}_{2 / 3} \mathrm{FePO}_{4}$. Green marks indicate the positions of the superstructure reflections. [-110] ${ }_{\text {Pnma }}$ (left) and $[001]_{\text {Pnma }}$ (right) EDPs show a clear threefold superstructure in the ab plane of the original Pnma lattice. Reproduced with permission. ${ }^{35}$ (Bottom) Annular bright-field (ABF) micrographs showing that the Li-ions occupy every other row in the partially delithiated $\mathrm{LiFePO}_{4}$ : (a) pristine material with the atomic structure of $\mathrm{LiFePO}_{4}$; (b) fully charged state with the atomic structure of $\mathrm{FePO}_{4}$, shown for comparison; and (c) half-charged state showing the Li staging. Note that Li sites are marked by yellow circles, whereas the delithiated sites are marked by orange circles. Reproduced with permission. ${ }^{36}$

definitive structure can be attributed to the predominant charge ordering of $\mathrm{Fe}$ ions followed by the redistribution of $\mathrm{Li}$-ions, thereby optimizing the local interaction. The charge transport at the interphase region across the biphasic boundary is the primary stage of the solid-state electrochemical reactions, in which the Li concentrations and the valence state of $\mathrm{Fe}$ significantly deviate from the equilibrium end members (that is, $\mathrm{LiFePO}_{4}$ and $\mathrm{FePO}_{4}$ ). ${ }^{35}$

$\mathrm{Gu}$ et al. $^{36}$ have directly observed Li-ions in partially delithiated $\mathrm{LiFePO}_{4}$ through aberration-corrected ABF-STEM, and have found that the remaining Li-ions preferably occupy every second layer (Figure 3, bottom), similar to the staging phenomenon that occurs in some layered intercalation compounds. These results challenge the previously proposed two-phase separation mechanism. ${ }^{36}$ Furthermore, a highly ordered $\mathrm{LiFePO}_{4}-\mathrm{FePO}_{4}$ interface with an alternative $\mathrm{Li}$ staging structure perpendicular to the $b$ axis and along the $a$ axis has been observed in a partially (by chemical processes) delithiated $2 \% \mathrm{Nb}$-doped $\mathrm{LiFePO}_{4}$ with a particle size of $\sim 200 \mathrm{~nm}{ }^{37,38}$ The formation of the Li-staging configuration is mainly attributed to the Fe center-mediated interlayer $\mathrm{Li}-\mathrm{Li}$ interactions that represent an indirect electrostatic force. ${ }^{39}$ However, the origin of both the ordered $\mathrm{Li} /$ vacancy staging at half-charged states $\left(\mathrm{Li}_{1 / 2} \mathrm{FePO}_{4}\right)$ and the polaronic charge-ordered superstructure in $\mathrm{Li}_{2 / 3} \mathrm{FePO}_{4},{ }^{35,40}$ cannot be simply explained by the electrostatic repulsion of the intercalated Li-ions, and it will be further discussed in the 'Charge ordering and the Jahn-Teller effect' section.

The intermediate structure can act as a buffer that relaxes the lattice mismatch between the two end members $\left(\mathrm{Li}_{\mathrm{x}} \approx 0 \mathrm{FePO}_{4}\right.$ and $\mathrm{Li}_{\mathrm{x} \approx 1-}$ $\mathrm{FePO}_{4}$ ), thereby accelerating the phase boundary movement, as proposed by Orikasa et al. ${ }^{31}$ This Li-deficient and mixed-valent state is expected to induce higher ionic/electronic conductivity than pristine $\mathrm{LiFePO}_{4}$ and $\mathrm{FePO}_{4}$, thereby potentially enhancing the reaction kinetics. ${ }^{41}$

\section{Conversion reaction}

Understanding the microscopic mechanisms involved in the electrochemical reaction and the material degradation processes is crucial for the rational design of high-performance LIB and NIB devices. Lithiation/sodiation-induced volume expansion, plasticity and pulverization of electrode materials are the major mechanical effects that negatively affect the performance and lifetime of high-capacity anodes in rechargeable batteries. ${ }^{42}$

Nanowires. Huang et al. ${ }^{43}$ have proposed an in situ TEM experimental setup for imaging a $\mathrm{SnO}_{2}$ nanowire electrode in an open electrochemical cell (Figure 4, top). A reaction front progressively propagates along the $\mathrm{SnO}_{2}$ nanowire during charging, thus causing the nanowire to swell, elongate and spiral. The reaction front is a 'Medusa zone' containing a high density of mobile dislocations that continuously nucleates and absorbs at the moving front, thereby allowing for a ca. $250 \%$ volume change while preventing fracturing at practical charging rates. This dislocation cloud reveals large in-plane misfit stresses that serve as a structural precursor for the electrochemically driven solid-state amorphization. ${ }^{43}$

Figure 4 (bottom) shows a detailed structure and phase characterization of the $\mathrm{SnO}_{2}$ nanowire before and after charging. Figure $4 \mathrm{a}$ reveals the presence of a region with a high density of dislocations separating the nonreacted and reacted segments of the nanowire. The nanowire is monocrystalline before the reaction, as revealed by the EDP (Figure 4b). Immediately after charging, the nanowire shows a dark gray contrast (Figure $4 \mathrm{a}$ ), and the EDP of most areas shows amorphous haloes (Figure 4d). After prolonged charging, the nanowire comprising small nanocrystals disperses in an amorphous matrix (Figure 4f), and the EDP shows diffraction rings superimposed on diffuse amorphous halos (Figure 4e). These diffraction rings can be indexed as hexagonal $\mathrm{Li}_{\mathrm{X}} \mathrm{Sn}$ (orange indices in Figure 4e) and tetragonal Sn (black indices in Figure 4e) phases. The EDP from the reaction front (Figure 4c) shows diffraction 


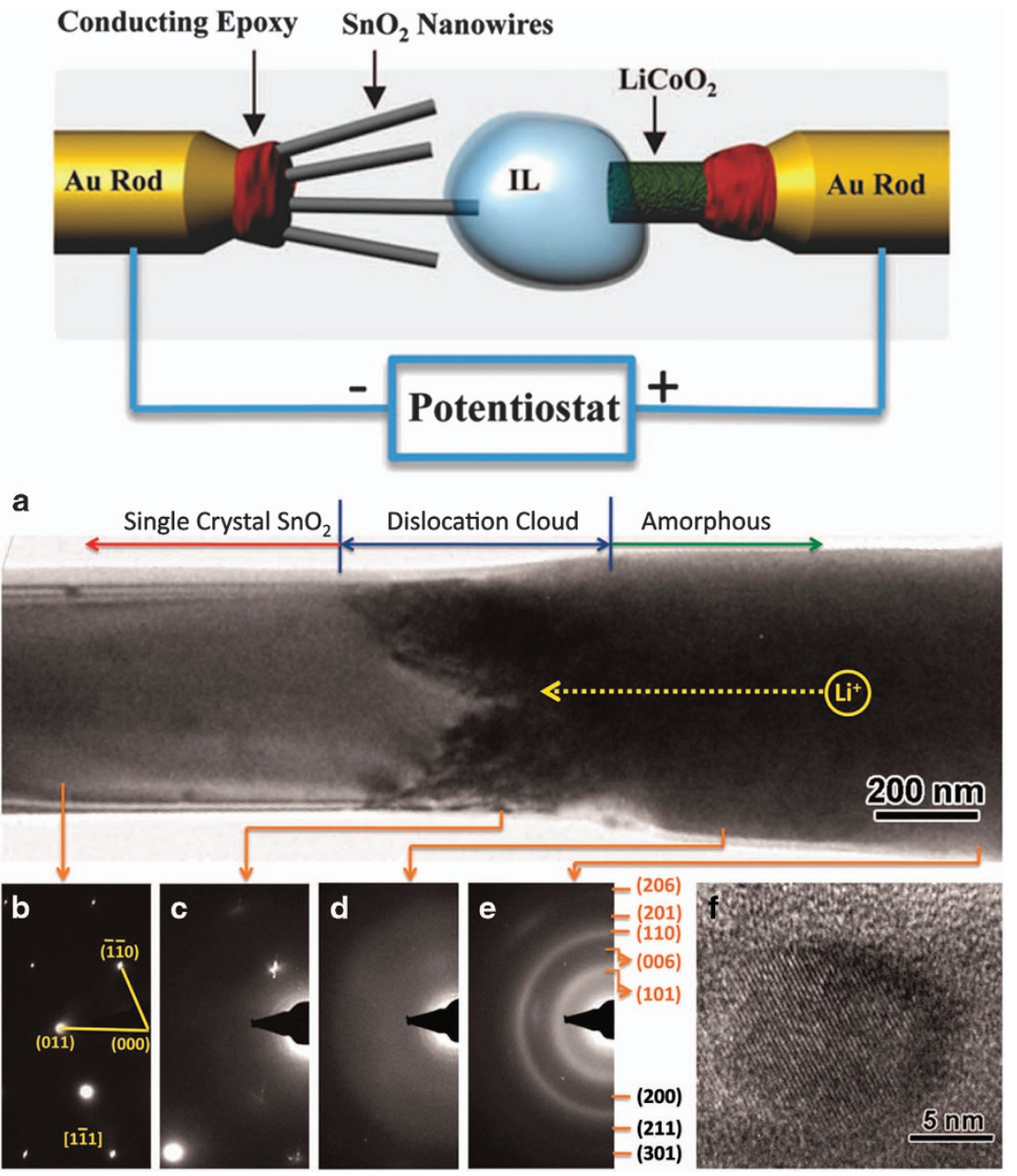

Figure 4 (Top). Schematic of the experimental setup. (Bottom) Structural and phase characterization of one $\mathrm{SnO}_{2}$ nanowire anode during charging at $-3.5 \mathrm{~V}$ against the $\mathrm{LiCOO}_{2}$ cathode. (a) TEM image of the nanowire containing a reaction front (dislocation cloud) that separates the reacted (amorphous) and nonreacted (single-crystal $\mathrm{SnO}_{2}$ ) areas. (b-e) EDP taken from different sections of the nanowire. (f) High-resolution transmission electron microscopy (HRTEM) image from a charged nanowire, showing that $\mathrm{Sn}$ nanoparticles are dispersed in an amorphous matrix. Reproduced with permission. ${ }^{43}$

spots superimposed on a diffuse scattering background. These diffraction spots are similar to those of the nonreacted nanowire, except that the zone axis of the former is slightly tilted with respect to the latter. Overall, the $\mathrm{SnO}_{2}$ is initially reduced to nanocrystalline $\mathrm{Sn}$ and amorphous $\mathrm{Li}_{2} \mathrm{O}$, thereby suggesting the following reduction reaction:

$$
4 \mathrm{Li}+\mathrm{SnO}_{2}+4 \mathrm{e}^{-} \rightarrow 2 \mathrm{Li}_{2} \mathrm{O}+\mathrm{Sn}
$$

This is the 'forming stage', producing a Sn-containing anode. After this initial phase transformation, the operation of the $\mathrm{Sn}-\mathrm{LiCoO}_{2}$ battery is based on the following reversible reaction:

$$
\mathrm{Sn}+\mathrm{xLi}^{+}+\mathrm{xe}^{-} \leftrightarrow \mathrm{Li}_{\mathrm{x}} \mathrm{Sn}(0 \leqslant \mathrm{x} \leqslant 4.4)
$$

Zhong et al. $^{44}$ have further revealed the atomic-scale lithiation mechanism of an individual $\mathrm{SnO}_{2}$ nanowire with a flooding geometry after contact with the electrolyte. The lithiation is initiated after the formation of multiple stripes several nanometers in width, parallel to the (020) plane traversing the entire wires that serve as multiple reaction fronts for subsequent lithiation stages. Within the stripes, a high density of dislocations and an enlarged interplane spacing are present, thereby providing an effective path for Li-ion transport. ${ }^{44}$ Geometric phase analysis and density functional theory (DFT) simulation have revealed that Li-ions preferentially diffuse along the [001] direction in the $\{200\}$ planes of the $\mathrm{SnO}_{2}$ nanowires, thereby generating the above-mentioned lattice expansion and dislocation behavior. ${ }^{45}$ At later lithiation stages, the formation of crystalline $\mathrm{Sn}$ and $\mathrm{Li}_{\mathrm{x}} \mathrm{Sn}$ particles in the $\mathrm{Li}_{2} \mathrm{O}$ matrix is observed, a result nearly consistent with results from the in situ TEM study of a miniature battery using an ionic liquid-based electrolyte. ${ }^{46}$

Nanoparticles. An in situ TEM setup for nanomaterials is illustrated in Figure 5a. $\mathrm{A} \mathrm{FeF}_{2}-\mathrm{C}$ composite electrode was made with as-synthesized $10-20 \mathrm{~nm} \mathrm{FeF}_{2}$ particles dispersed on thin carbon films. The real-time morphological changes during lithiation were recorded by $\mathrm{ADF}$ imaging (Figures $5 \mathrm{~b}$ and $\mathrm{c}$ ). The reaction front propagates extremely rapidly and sweeps across the particles in region I within a few seconds. In contrast, the reaction is delayed in subsequent regions (by $\sim 10 \mathrm{~min}$ in region II and no reaction occurs in region III even after more than $20 \mathrm{~min}$ ). The reduced activity in regions II and III is probably because of the poor contact between the particles and current collector that inhibits ion and electron transport. 


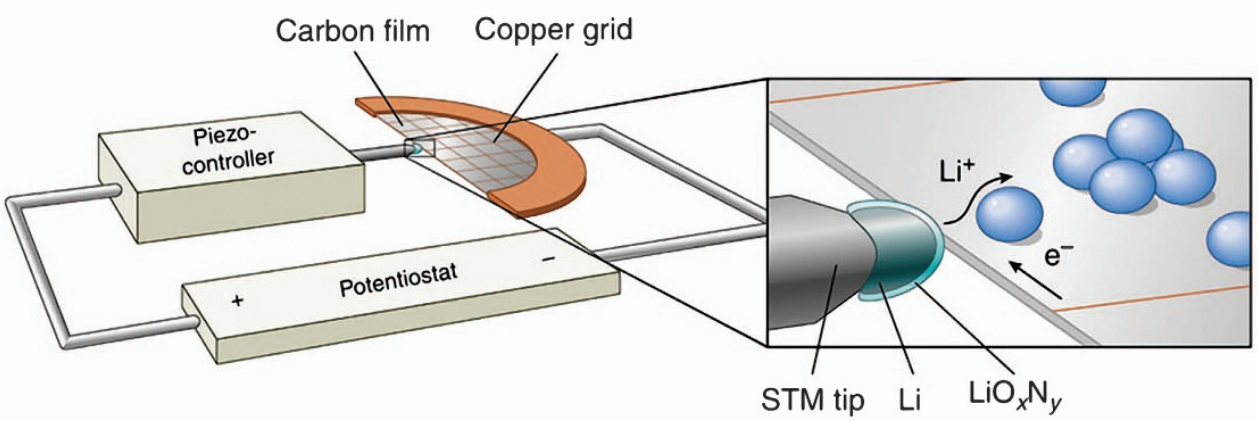

b

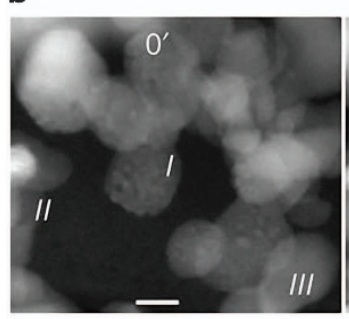

C
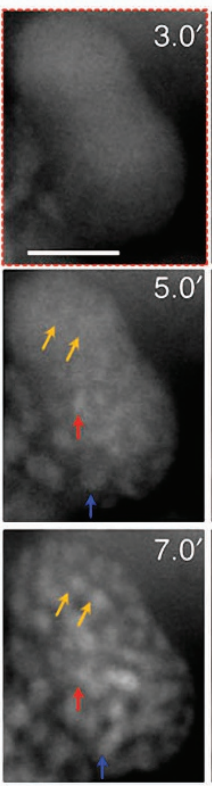
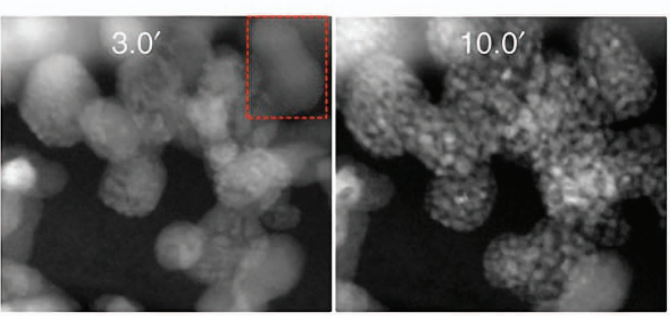

d
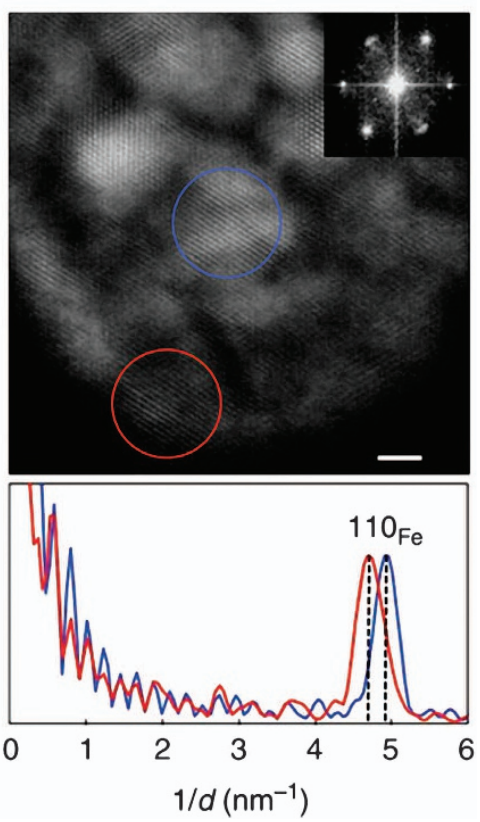

Figure $5 \mathrm{Li}$ conversion of $\mathrm{FeF}_{2}$, as monitored in real time. (a) Schematic of the electrochemical cell used for the in situ TEM measurements. (b) Time-lapse images from a collection of particles that react with Li-ions coming from the lower right. The lithiation proceeds immediately in region (I) but is delayed and absent in regions (II) and (III), respectively. Scale bar is $10 \mathrm{~nm}$. (c) Morphological evolution of a single $\mathrm{FeF}_{2}$ nanoparticle, revealing the rapid formation of the ultrafine (sub-nanometric) Fe particles on the surface, followed by the gradual formation of larger ones (1-3 nm) within the domains of the original FeF 2 particle (arrows used to identify specific Fe particles). Scale bar is $10 \mathrm{~nm}$. (d, up) Lattice image of Fe particles converted from a single FeF 2 particle (top) along the [-111] zone axis, according to the FFT pattern (inset). (d, down) Intensity profiles of the FFT patterns (bottom) of the Fe lattice in the nearsurface region (red circle) and central region (blue circle). Scale bar is $2 \mathrm{~nm}$. Reproduced with permission. ${ }^{47}$

The time-lapse images in Figure 5c show the electrochemical conversion of a single particle. A rapid surface reaction is triggered, thus leading to the formation of small, sub-nanometric Fe particles, followed by a reaction in the bulk that results in slightly larger (1$3 \mathrm{~nm}$ ) Fe particles. Lithiation under an external bias clearly shows two different timescales for inter- and intra-particle $\mathrm{Li}^{+}$transport. The Liions appear to move quickly via surface diffusion along the carbon film and $\mathrm{FeF}_{2}$ particles, and then they penetrate into the bulk at a significantly lower rate. During the conversion period, no observable coarsening of the newly formed Fe nanoparticles is seen (Figures $5 \mathrm{~b}$ and c). This observation suggests an immediate decomposition reaction that occurs locally, with the formed LiF effectively blocking the interparticle Fe diffusion, thus preventing the coarsening. ${ }^{47-49}$

\section{Alloying reaction}

$\mathrm{Si}$ is an attractive anode material for LIBs because it has a low discharge potential while exhibiting a very high theoretical charge capacity $\left(4200 \mathrm{mAh}^{-1}\right)$. The main challenges associated with $\mathrm{Si}$ 
a

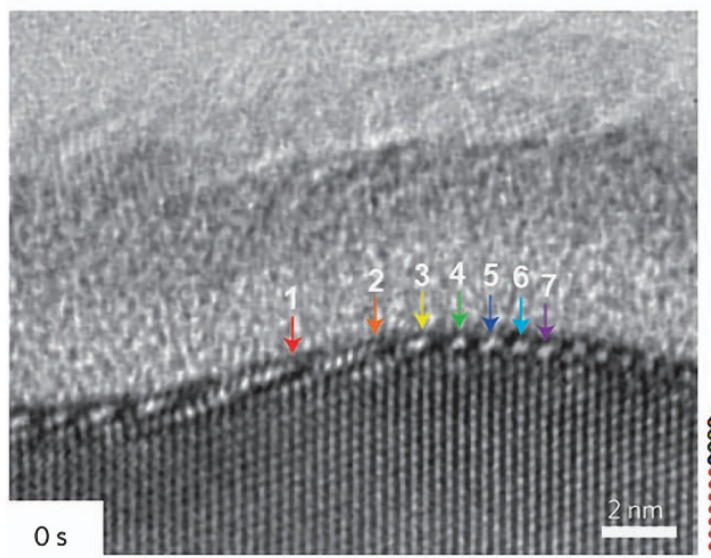

b

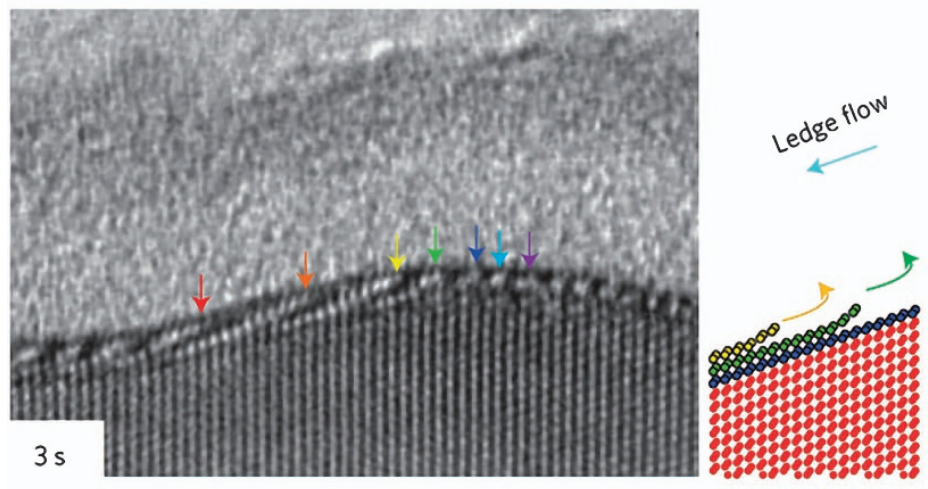

c

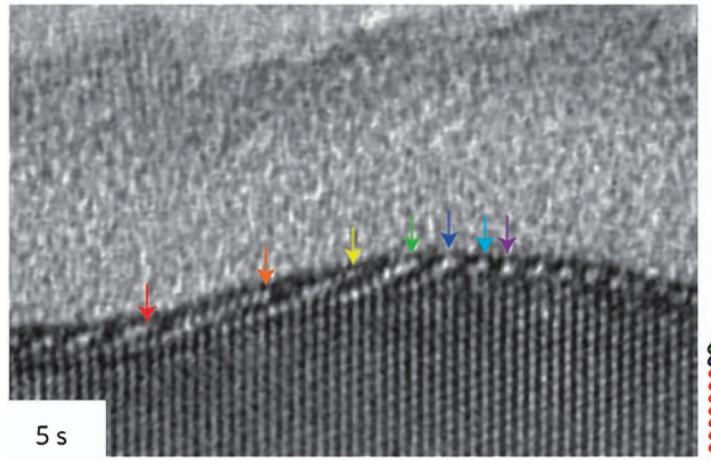

d
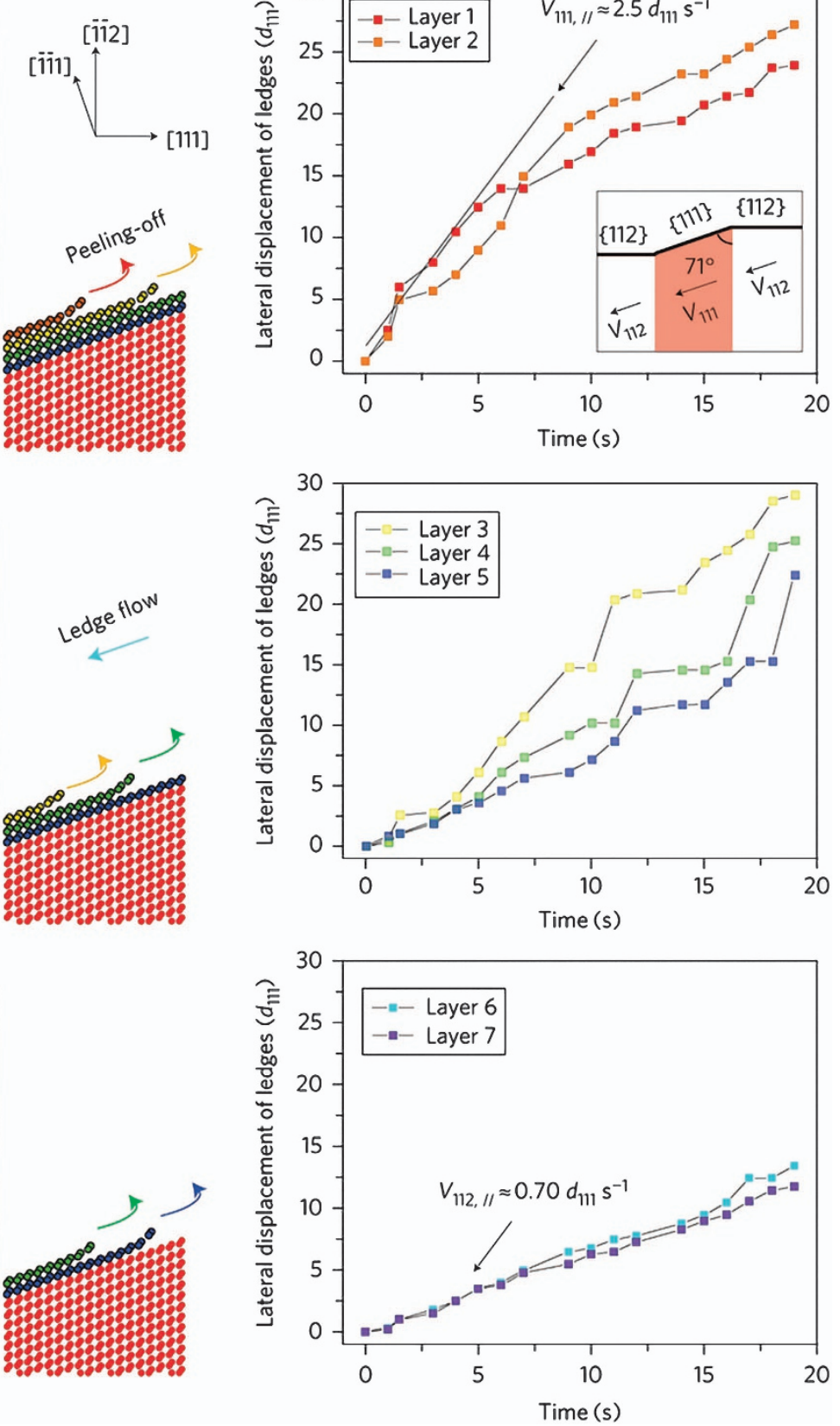

Figure 6 Ledge mechanism of lithiation in c-Si. (a-c) HRTEM image sequences showing the lithiation process by lateral ledge flow (marked by colored arrows) in the amorphous/crystalline interface $(\mathrm{ACl})$ and the simultaneous peeling-off of the $\{111\}$ planes over $5 \mathrm{~s}$. The $\mathrm{ACl}$ is $3-4$ atomic layers thick, and the atomic layers are distorted and different from both the mottled contrast in the top a-Lix Si layer and the regular lattice in the bottom c-Si. (d) Schematic showing the peeling-off of the $(\overline{11} 1)$ atomic layers by the continuous in-plane ledge flow during lithiation. (e) Lateral displacement of the seven ledges projected to the horizontal [111] direction versus time. Ledges can move faster on the $\{111\}$ facet and slower on the $\{112\}$ planes. The ledge flow speed is inversely proportional to the ledge density that gives a constant radial etching rate. Reproduced with permission. ${ }^{54}$

anodes are the structural degradation, and especially the instability of the solid-electrolyte interface caused by the large volume change (ca. 300\%) during cycling, the occurrence of side reactions with the electrolyte and the low volumetric capacity of nanometric silicon. The development of $\mathrm{Si}$ anodes has stimulated the search for high power and high energy LIBs. ${ }^{50-52}$ Despite the intensive study of this material, the atomistic mechanism involved in the electrochemical reaction of $\mathrm{Si}$ anodes remains unclear.
Liu et al. have observed a sharp interface ( $c a .1 \mathrm{~nm}$ thick) between crystalline $\mathrm{Si}$ and amorphous $\mathrm{Li}_{\mathrm{X}} \mathrm{Si}$ alloy phases in single-crystalline $\mathrm{Si}$ nanowires during dynamic lithiation. ${ }^{53}$ The lithiation kinetics are controlled by the interface migration that occurs through a ledge mechanism involving the lateral movement of ledges on the close-packed $\{111\}$ planes. Figure 6 presents close-up views of the atomic structure of an amorphous/crystalline interface (ACI) and unambiguously reveals a ledge mechanism for c-Si lithiation. The 
ledges, consisting of successive inclined ( $\overline{11} 1$ ) atomic planes, are marked by seven arrows (Figures $6 \mathrm{a}-\mathrm{c}$ ), and the red dot arrays represent a two-dimensional projection along the [1-10] direction of the pristine Si lattice within the Si nanowire core (Figure 6d). The HRTEM images of Figures $6 a-c$ show that the atomic arrangement at the ACI is highly distorted and exhibits a unique striped contrast with a disordered structure.

A ledge-mediated mechanism for solid-state amorphization is suggested by the dynamic observation of the ACI migration, with $\mathrm{Li}$ atoms being squeezed into the large open space between two neighboring $(\overline{11} 1)$ bilayers (that is, two closely spaced $(\overline{11} 1)$ atomic planes, such as Aa in the diamond structure with an AaBbCc stacking).
Thus, the $(\overline{11} 1)$ bilayer spacing increases and leads to peeling of the top (111) bilayer. Meanwhile, the ledges (that is, atomic steps) flow along the (111) plane, and the Si atoms at the ledges 'dissolve' into the $\mathrm{a}-\mathrm{Li}_{\mathrm{X}} \mathrm{Si}$ phase. As a result, the lithiation reaction proceeds by atomic removal from the Si surface (alloyed into the $\mathrm{a}-\mathrm{Li}_{\mathrm{x}} \mathrm{Si}$ shell) during the migration of the ledges. As illustrated in Figure $6 \mathrm{~d}$, the peeling of the $\{111\}$ facets occurs in a layer-by-layer manner through a lateral ledge flow in each layer.

Figure 6e plots the lateral displacement (projected to the horizontal [111] direction) of the seven ledges versus time. Interestingly, at a similar radial Li flux from the nanowire surface to the center in this short length scale of $c a .10 \mathrm{~nm}$, the speed of the ledge flow is inversely
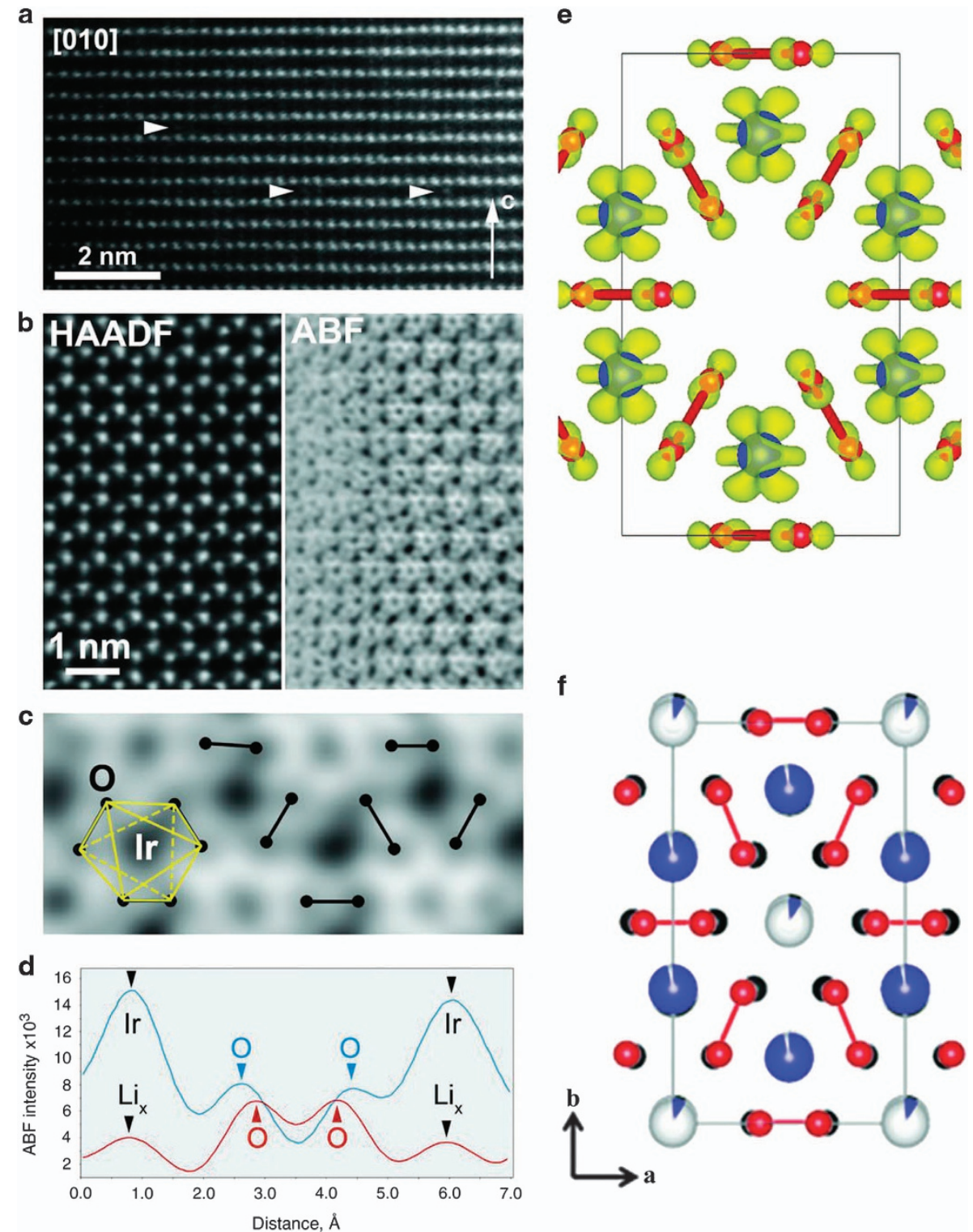

Figure 7 Structural changes in the oxygen sublattice. (a) [010] HAADF-STEM image of the charged $\mathrm{Li}_{0.5} \mathrm{IrO}_{3}$ sample showing the ordered sequence of the Ir layers that corresponds to the 01-type structure. $\mathrm{N}$ migration of the Ir cations to the Li layers is observed, and a few antisite point defects are marked with the arrowheads. (b) [001] HAADF-STEM and ABF-STEM images of the same sample. (c) Enlarged ABF-STEM image; the 0-0 pairs with short projected distances are marked with dumbbells, whereas the different $\mathrm{O}-\mathrm{O}$ pairs arise from twisting the opposite triangular faces of the $\mathrm{IrO}_{6}$ octahedra (shown in yellow). (d) $\mathrm{ABF}$ intensity profiles along the $\mathrm{O}-\mathrm{O}$ pairs with long (blue) and short (red) projected distances. (e) [001] projection of the $\mathrm{Li}_{0.5} \mathrm{IrO}_{3}$ in the $\mathrm{O}_{1}$ stacking configuration obtained from DFT calculations ( $\mathrm{Li}$ atoms are omitted for clarity, Ir atoms are shown in blue, $\mathrm{O}$ atoms are in red and the yellow surfaces represent the Fukui orbitals). (f) Structure of the charged Li-Ir-O material obtained from neutron powder diffraction overlaid on the pristine structure, shown in black, that clearly illustrates the formation of $0-0$ dimers. Reproduced with permission. ${ }^{58}$ 
a

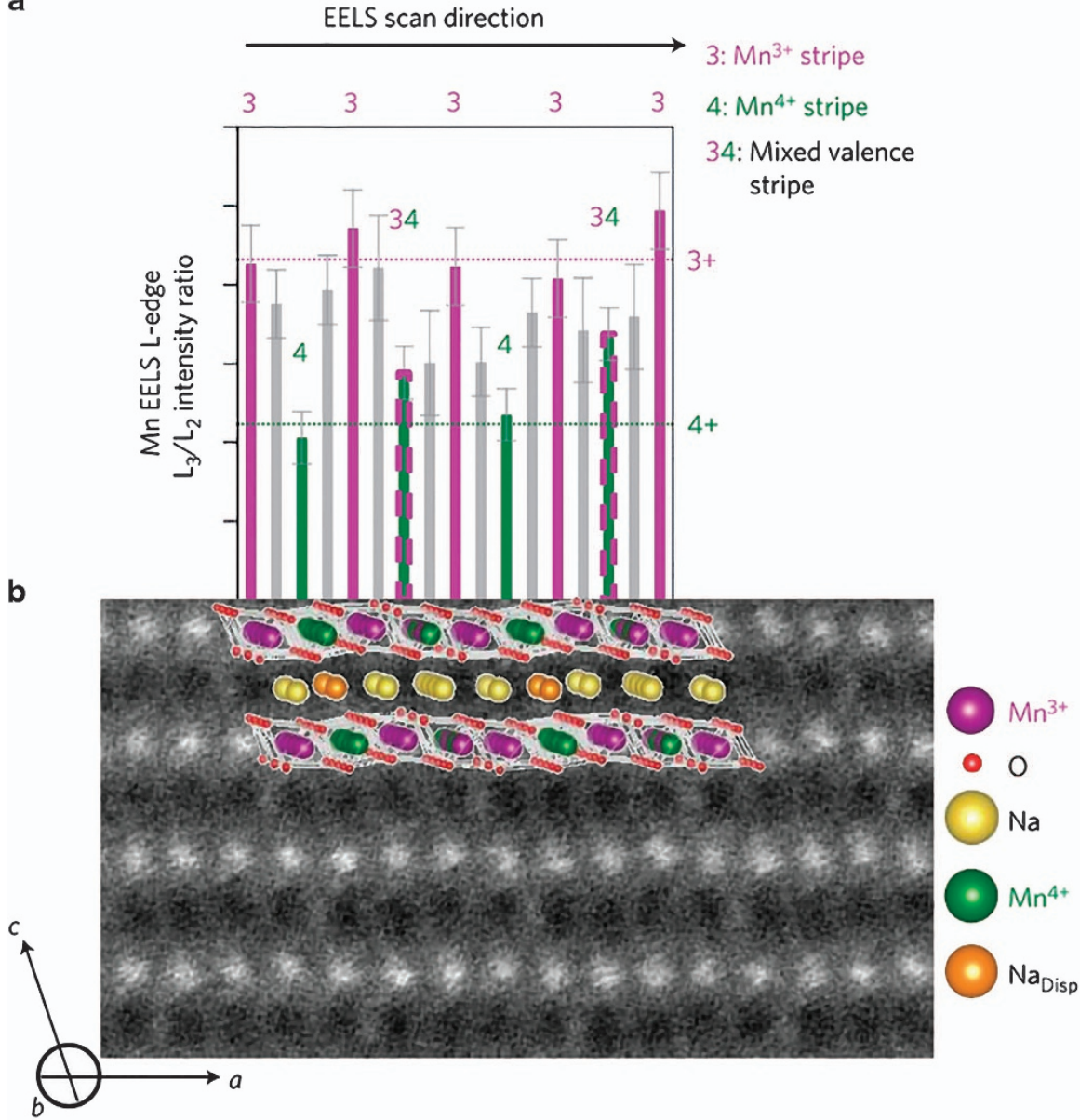

C L L

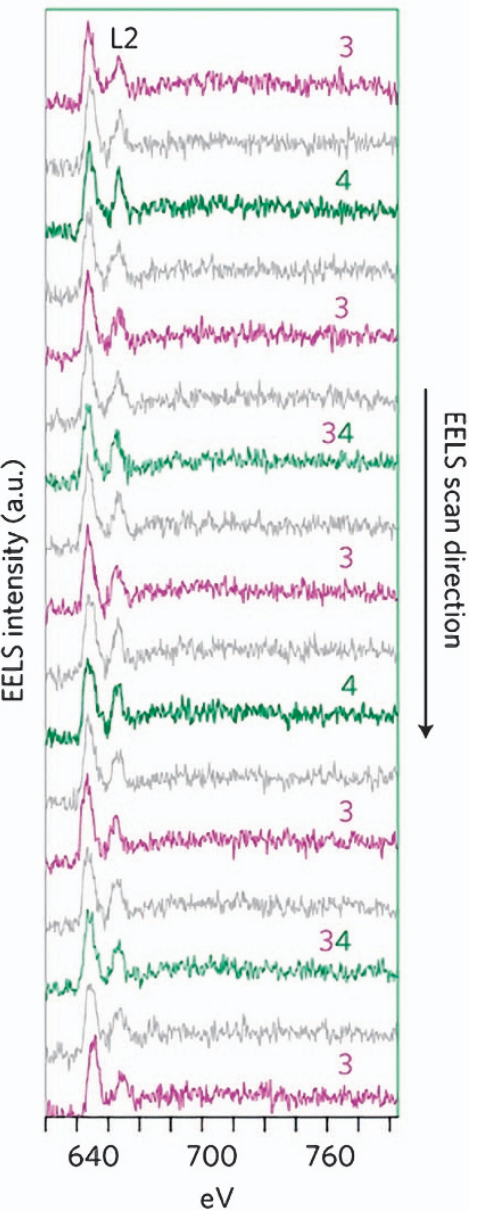

Figure 8 Atomic-scale STEM image visualizing the cooperative Jahn-Teller effect (CJTE); the STEM EELS shows the Mn charge ordering. (a) Mn EELS L $_{3} / \mathrm{L}_{2}$ peak ratio at each $\mathrm{Mn}$ [010] atomic column site along the STEM-EELS scanning direction of [100]; the dashed lines show the ratios that correspond to the standard $\mathrm{MnO}_{2}$ and $\mathrm{Mn}_{2} \mathrm{O}_{3}$ samples. Error bars are determined from the errors introduced from background subtraction and data fluctuation among spectra. (b) STEM image along the [010] zone axis shows the periodic distortion of the $\mathrm{Mn}$ ab plane and the intensity modulation of the Na plane, a result quantitatively consistent with the superstructure model in the inset (the $\mathrm{Na}_{\text {disp }}$ ball indicates $\mathrm{Na}$ ions displaced by $<0.5 \AA$ from their original lattice position). (c) $17 \mathrm{Mn} \mathrm{L}_{2,3}$-edge EEL spectra after background subtraction that provide the $\mathrm{L}_{3} / \mathrm{L}_{2}$ ratios shown in (b). Reproduced with permission. ${ }^{68}$

proportional to the ledge density at the ACI, thereby resulting in a nearly constant radial lithiation speed. The ledges pass $\sim 2.5$ vertical (111) planes per second (spacing $\mathrm{d}_{111}=0.31 \mathrm{~nm}$ ) when they are on the inclined $(\overline{11} 1)$ facet. This speed is 3.5 times faster than that observed when the ledges are sitting on the horizontal (112) ACI $\left(0.70 \mathrm{~d}_{111} \mathrm{~s}^{-1}\right)$. The amorphous $\mathrm{Li}_{\mathrm{x}} \mathrm{Si}$ alloy is produced by such a ledge flow process through the layer-by-layer peeling of the $\{111\}$ atomic facets, thus resulting in the orientation-dependent mobility of the interface. ${ }^{53,54}$

\section{CHARGE COMPENSATION}

Mixed ion-electron conducting solid materials have many important applications as energy storage materials in batteries, thermoelectric energy conversion devices and catalysts for fuel-cell reactions. The reversible energy storage in rechargeable batteries is a typical example. However, despite a very long history of research on rechargeable batteries and their widespread use in our daily life, the correlated science for multiple condensed mobile species in solids remains to be established. Thus, one of the key issues lies in determining how opposite charges (that is, ions and electrons) move together in mixed conductors using the typical electrode materials of rechargeable batteries. $^{35}$

\section{Anionic redox chemistry}

During the charge/discharge of LIB cathodes by de- and reintercalation of Li-ions, the electroneutrality is maintained by $\mathrm{TM}$ redox chemistry, thereby limiting the charge that can be stored. However, this mechanism is insufficient to account for the high capacities exhibited by the new generation of Li-rich layered or rock-salt (for example, $\mathrm{Li}_{3} \mathrm{NbO}_{4},{ }^{55}$ and $\mathrm{Li}_{4} \mathrm{Mn}_{2} \mathrm{O}_{5},{ }^{56}$ ) oxides that show an unusual Li reactivity. Luo et al. ${ }^{57}$ have reported that $\mathrm{O}$ is extracted from the lattice during the cathode charging without any signs of $\mathrm{O}_{2}$ evolution. They have demonstrated that, in addition to $\mathrm{O}$ loss, $\mathrm{Li}^{+}$ removal is charge compensated by the formation of localized electron holes on the $\mathrm{O}$ atoms coordinated by $\mathrm{Mn}^{4+}$ and $\mathrm{Li}^{+}$ions, and this mechanism promotes the localization (not the formation) of true $\mathrm{O}_{2}{ }^{2-}$ (peroxide, $\mathrm{O}-\mathrm{O} c a .1 .45 \AA$ ) species. The quantity of charge compensated by both $\mathrm{O}$ removal and the formation of electron holes on the $\mathrm{O}$ atoms has been estimated and, in the case described here, the latter dominated. ${ }^{57}$ 
However, the observation of the $\mathrm{O}-\mathrm{O}$ bonding pattern and a satisfactory explanation for the irreversible changes that occur during the first delithiation process are lacking in the literature. Using $\mathrm{Li}_{2} \mathrm{IrO}_{3}$ as a model compound, McCalla et al. ${ }^{58}$ have visualized the $\mathrm{O}-\mathrm{O}$ dimers via ABF-STEM and neutron diffraction and have established the fundamental relationship between the anionic redox process and the evolution of the $\mathrm{O}-\mathrm{O}$ bonding in layered oxides. The projected symmetry of the $\mathrm{IrO}_{6}$ octahedra was expected to be close to a sixfold symmetry that corresponds to approximately equal $\mathrm{O}-\mathrm{O}$ separations throughout. However, the shape of these octahedra, as observed by [001] ABF-STEM imaging, clearly suggests a threefold symmetry owing to the onset of shortened (Figure 7c, black dumbbells) and lengthened (Figure 7c, left blank) projected $\mathrm{O}-\mathrm{O}$ separations. The values of the projected $\mathrm{O}-\mathrm{O}$ separations have been estimated from a distribution histogram that reveals peaks centered at 1.56 and $1.83 \AA$ (Figure 7d). These values represent the average shortened and lengthened projected $\mathrm{O}-\mathrm{O}$ distances. DFT calculations have revealed shortened projected $\mathrm{O}-\mathrm{O}$ distances for pairs of $\mathrm{O}$ atoms (joined by red lines), lying between two Ir atoms. Figure 7e shows the Fukui function that probes the change in the electron density as a result of an infinitesimal change in the total number of electrons. The shape of the Fukui function around the $\mathrm{O}$ atom shows overlapping lobes along the axis, joining the $\mathrm{O}-\mathrm{O}$ pairs with short separations, a result consistent with the expected partially empty antibonding $\sigma^{\star}$ orbitals of peroxolike species. ${ }^{58}$

In contrast, Ceder and colleagues ${ }^{59}$ have proposed that $\mathrm{Li}-\mathrm{O}-\mathrm{Li}$ configurations rather than TM-O configurations in the cationdisordered Li-excess cathode oxides can lead to orphaned $\mathrm{O}$ states and introduce labile $\mathrm{O}$ electrons that participate in the redox reaction. The unhybridized $\mathrm{O} 2 p$ states induced by the Li-O-Li configurations have higher energies than the hybridized $\mathrm{O} 2 p$ states and as a result are more easily oxidized. The conditions for peroxo-like $\mathrm{O}-\mathrm{O}$ bond formation and the competition between the TM and $\mathrm{O}$ redox are dependent on the changes in the local $\mathrm{O}$ coordination environment during delithiation. Theoretical or experimental studies on the local structural components (for example, the TM-O vs Li-O coordination, bond hybridization and band structure) will provide a new direction for the design of high-energy-density cathode materials. ${ }^{59}$

\section{Electronic structure}

TM cation migration and TM-O coordination. For those phase transformations that involve the rearrangement of TM cations in octahedral sites within a fixed cubic closed-packed oxide framework (for example, the transformation of layered $\mathrm{Li}_{\mathrm{X}} \mathrm{MnO}_{2}$ to spinel), it has been indicated that the low-energy pathway for TM migration between octahedral sites involves the shared nearest-neighbor tetrahedral site (that is, $\mathrm{O}_{\mathrm{h}} \rightarrow \mathrm{T}_{\mathrm{d}} \rightarrow \mathrm{O}_{\mathrm{h}}$ ) rather than a direct transition between octahedral sites (that is, $\mathrm{O}_{\mathrm{h}} \rightarrow \mathrm{O}_{\mathrm{h}}$ ). ${ }^{60}$ Thus, the lower the energy change for the TM ion migration between octahedral and tetrahedral coordination sites, the more easily these ions will be rearranged in a cubic closed-packed oxide, when the oxide transforms from a metastable structure to a stable one. As a result, the resistance to the transformation of metastable TM oxides within a cubic closedpacked oxygen sublattice (for example, $\mathrm{Li}_{\mathrm{x}} \mathrm{MnO}_{2}$ with $\alpha-\mathrm{NaFeO}_{2}$ structure) depends on the relative stability of the TM in the octahedral coordination as compared with that in the tetrahedral coordination. The availability of empty tetrahedra without any cations occupying the nearest-neighbor face-sharing octahedra is also an important factor that determines the ability of TM ions to migrate through a cubic closed-packed oxide. Such tetrahedral interstitial sites provide a relatively low-energy migration pathway by avoiding the highly repulsive interaction between face-sharing cations. ${ }^{61}$

As discussed in 'Interface structure' section, cation migration most probably occurs at the solid-electrolyte interface, thus resulting in surface reconstruction. More specifically, Sathiya et al. ${ }^{62}$ have noted that the migration of cations between TM metal layers and Li layers is an intrinsic feature of the charge-discharge process that increases the trapping of metal ions in the interstitial tetrahedral sites. A correlation between these trapped ions and the voltage decay has been established by expanding the study to both $\mathrm{Li}_{2} \mathrm{Ru}_{1-\mathrm{y}} \mathrm{Sn}_{\mathrm{y}} \mathrm{O}_{3}$ and $\mathrm{Li}_{2} \mathrm{RuO}_{3}$, and the slowest decay has been found to occur for the cations with the largest ionic radii. ${ }^{62}$

Because $\mathrm{O}$ provides the octahedral framework for cations, the cation-anion coordination strongly influences the migration of both $\mathrm{TM}$ and Li-ions. For layered oxides after cycling, the magnitude of the O pre-peak and the valence of TM decreases at the near-surface region compared with the bulk region. ${ }^{63}$ In TM oxides, the O pre-peak originates from the hybridization between the $\mathrm{O} 2 p$ and unoccupied TM $3 d$ orbitals. The decrease in magnitude of this peak corresponds to a greater filling of the Mn $3 d$ orbital, a result indicative of a lower number of $\mathrm{O}$ atoms in the coordination shell of $\mathrm{Mn} .{ }^{64} \mathrm{Li}$ and $\mathrm{O}$ deficiencies at the surface of $\mathrm{LiMn}_{2} \mathrm{O}_{4}$ nanoparticle have been revealed by EELS analysis conducted with a Cs-corrected STEM. Thus, an ordered tetragonal $\mathrm{Li}_{1-}{ }_{\mathrm{x}} \mathrm{Mn}_{2} \mathrm{O}_{4-\delta}$ phase has been detected along with the structure and composition changes at the surface region of the nanoparticle. An O-vacancy ordering has been confirmed to exist at the surface by HAADF-STEM. ${ }^{64}$ The surface TM reduction is typically accompanied by $\mathrm{O}$-vacancy formation owing to the charge compensation effect. The formation of (dilute) $\mathrm{O}$ vacancies and their roles in assisting TM ion diffusion have been further investigated using first-principle calculations. The activation barriers for TM diffusion in the presence of $\mathrm{O}$ vacancies are drastically reduced, thus allowing room temperature diffusion. ${ }^{65}$

Charge ordering and the Jahn-Teller effect. The prevalence of electron or ion conduction during electrochemical reactions remains an open question in the field of mixed ion-electron conductors. As discussed in 'Intermediate transition' section, the superstructure in metastable $\mathrm{Li}_{2 / 3} \mathrm{FePO}_{4}$ and $\mathrm{Na}_{2 / 3} \mathrm{FePO}_{4}$ can be attributed to a predominant charge ordering of $\mathrm{Fe}$ ions followed by the redistribution of $\mathrm{Li}$ and $\mathrm{Na}$ ions, respectively, thus optimizing the local interaction. Through electron diffraction, a similar charge ordering has been found in various battery materials such as $\mathrm{Na}_{\mathrm{x}} \mathrm{CoO}_{2}(0.15<\mathrm{x}<0.75)$ and $\mathrm{LiMn}_{2} \mathrm{O}_{4}$. An extensive series of ordered $\mathrm{Na}$ ion-Na vacancy superlattices has been observed beyond the hexagonal structure. The most strongly developed superlattice has been found for the $\mathrm{Na}_{0.5} \mathrm{CoO}_{2}$ composition, displaying $\mathrm{Co}^{3+} / \mathrm{Co}^{4+}$ charge ordering at low temperatures. ${ }^{66}$ Meanwhile, charge ordering is accompanied by simultaneous orbital ordering owing to the Jahn-Teller effect in $\mathrm{Mn}^{3+}$ ions. $^{67}$

Ceder and colleagues ${ }^{68}$ have provided direct STEM imaging evidence that the superstructure of $\mathrm{Na}_{5 / 8} \mathrm{MnO}_{2}$ is mainly controlled by Jahn-Teller distortions, thus inducing specific long-range $\mathrm{Na}-\mathrm{V}_{\mathrm{Na}}$ interactions through $\mathrm{Mn}$ charge and $d$-orbital orderings rather than by electrostatic interactions. The cooperative Jahn-Teller effect refers to the correlation of distortions that arise from individual Jahn-Teller centers in complex compounds. This effect usually induces strong coupling between the static or dynamic charge, orbital and magnetic ordering. ${ }^{68}$ In the $Z$-contrast image shown in Figure 8 b, each dot corresponds to either a $\mathrm{Na}$ or a $\mathrm{Mn}$ atomic stripe projected along the [010] or the $b$ direction. The periodic intensity modulation of one 
bright dot and three dark dots in the Na plane is proportional to the $\mathrm{Na}$ concentration in these stripes. Mn charge ordering has been observed in both STEM-EELS measurements (Figure 8a and c), in which the $\mathrm{L}_{3} / \mathrm{L}_{2}$ peak ratio is inversely proportional to the Mn charge state. There are three types of $\mathrm{Mn}$ atomic stripes: stripes for a pure $\mathrm{Mn}^{3+}$, a pure $\mathrm{Mn}^{4+}$ and alternating $\mathrm{Mn}^{3+}$ and $\mathrm{Mn}^{4+}$ ions. Because, unlike $\mathrm{Mn}^{4+} \mathrm{O}_{6}$, the $\mathrm{Mn}^{3+} \mathrm{O}_{6}$ octahedron is Jahn-Teller distorted, the periodic arrangement of these different stripes yields a cooperative Jahn-Teller effect that can be directly visualized by the rippling of the Mn layers, as shown in Figure 8b. In contrast to other alkali-vacancy systems, the $\mathrm{Na}$ ordering in $\mathrm{Na}_{\mathrm{x}} \mathrm{MnO}_{2}$ is controlled by the underlying combination of electrostatic and electronic structure interactions through the Jahn-Teller effect. ${ }^{68}$

\section{PERSPECTIVES}

The atomic structure, chemistry, phase transformation and charge compensation of the electrode materials in LIBs/SIBs are reviewed herein, as investigated primarily by advanced TEM. The focus of this review is the in-depth and dynamic understanding of the electrode materials under nonequilibrium conditions (that are similar to the usual operating conditions). Under these conditions, the behavior of the electrode materials is not dominated by the thermodynamic properties of the battery system. It has been shown that advanced TEM has the unique capabilities to identify surface reconstruction, interface structure, phase transformation, alloying reaction, anionic redox and even the electronic structure, among other aspects. The remarkable progress on aberration-corrected STEM techniques has enabled the direct characterization of both heavy and light elements in electrode materials. Specially designed open cell, liquid cell or all-solidstate microbatteries can further yield fruitful results in research in nonequilibrium electrochemical processes. Such in situ observations can contribute to elucidating the microscopic reaction mechanisms of electrode materials. The phase transformation of the electrode materials is accompanied by facile defect kinetics, including the generation and movement of the interface, dislocation and vacancy.

Furthermore, the origin of the redox process, the surface reconstruction and the phase transformation phenomena have been further explored in the framework of electron and lattice coupling. The results highlight the significance of the electronic structure on the electrochemical process. The knowledge obtained from operando TEM will provide guidance for developing better rechargeable batteries with high capacity, high rate capability and long cycle life characteristics.

Finally, battery materials containing $\mathrm{Li}$ are susceptible to electron-beam knock-on damage that may complicate the image interpretation. Under electron-beam irradiation, the surface and bulk of layered oxides undergo a phase transformation that is equivalent to that observed during charge-discharge cycling. ${ }^{69}$ The presence of $\mathrm{Li}$ and $\mathrm{O}$ vacancies generated by e-beam irradiation is considered to be the primary cause of the phase transformation. ${ }^{70,71}$ Therefore, special caution should be paid to the selection of e-beam energy and imaging conditions for easy interpretation. In contrast, e-beam irradiation can provide a feasible stimulus that mimics the effect of electrochemical cycling, thereby triggering the phase transformation of oxides. ${ }^{72}$ This will facilitate intensive studies on the localized nature of the structural transformation for battery materials.

\section{CONFLICT OF INTEREST}

The authors declare no conflict of interest.

\section{ACKNOWLEDGEMENTS}

This work was supported by the National Program on Key Basic Research Project (2014CB921002), the Strategic Priority Research Program of the Chinese Academy of Sciences (No XDB07030200) and the National Natural Science Foundation of China (No 51522212 and 51421002). YW and DX are grateful for financial support from the National Natural Science Foundation (No 51501085).

1 Larcher, D. \& Tarascon, J. M. Towards greener and more sustainable batteries for electrical energy storage. Nat. Chem. 7, 19-29 (2015).

2 Whittingham, M. S. Materials challenges facing electrical energy storage. MRS Bull. $\mathbf{3 3}$, 411-419 (2008).

3 Armand, M. \& Tarascon, J. M. Building better batteries. Nature 451, 652-657 (2008).

4 Dunn, B., Kamath, H. \& Tarascon, J.-M. Electrical energy storage for the grid: a battery of choices. Science 334, 928-935 (2011).

5 Gu, L., Xiao, D., Hu, Y.-S., Li, H. \& Ikuhara, Y. Atomic-scale structure evolution in a quasi-equilibrated electrochemical process of electrode materials for rechargeable batteries. Adv. Mater. 27, 2134-2149 (2015).

6 Muller, D. A., Sorsch, T., Moccio, S., Baumann, F. H., Evans-Lutterodt, K. \& Timp, G. The electronic structure at the atomic scale of ultrathin gate oxides. Nature 399 , 758-761 (1999).

7 Haider, M., Uhlemann, S., Schwan, E., Rose, H., Kabius, B. \& Urban, K. Electron microscopy image enhanced. Nature 392, 768-769 (1998).

8 Muller, D. A. Structure and bonding at the atomic scale by scanning transmission electron microscopy. Nat. Mater. 8, 263-270 (2009).

9 Yang, P. \& Tarascon, J.-M. Towards systems materials engineering. Nat. Mater. 11, 560-563 (2012).

10 Chiang, Y.-M. Building a Better Battery. Science 330, 1485-1486 (2010).

11 Zheng, H., Meng, Y. S. \& Zhu, Y. Frontiers of in situ electron microscopy. MRS Bull. 40 , 12-18 (2015).

12 Palacín, M. R. \& de Guibert, A. Why do batteries fail? Science 351, 1253292 (2016).

13 Choi, J. W. \& Aurbach, D. Promise and reality of post-lithium-ion batteries with high energy densities. Nat. Rev. Mater. 1, 16013 (2016).

14 Zheng, J., Xu, P., Gu, M., Xiao, J., Browning, N. D., Yan, P., Wang, C. \& Zhang, J.-G. Structural and chemical evolution of $\mathrm{Li}$ - and Mn-rich layered cathode material. Chem. Mater. 27, 1381-1390 (2015)

15 Lin, F., Markus, I. M., Nordlund, D., Weng, T.-C., Asta, M. D., Xin, H. L. \& Doeff, M. M. Surface reconstruction and chemical evolution of stoichiometric layered cathode materials for lithium-ion batteries. Nat. Commun. 5, 3529 (2014).

16 Goodenough, J. B. \& Kim, Y. Challenges for rechargeable Li batteries. Chem. Mater. 22, 587-603 (2010).

17 Xu, B., Fell, C. R., Chi, M. \& Meng, Y. S. Identifying surface structural changes in layered Li-excess nickel manganese oxides in high voltage lithium ion batteries: a joint experimental and theoretical study. Energy Environ. Sci. 4, 2223-2233 (2011).

18 Qian, D., Ma, C., More, K. L., Meng, Y. S. \& Chi, M. Advanced analytical electron microscopy for lithium-ion batteries. NPG Asia Mater. 7, e193 (2015).

19 Herle, P. S., Ellis, B., Coombs, N. \& Nazar, L. F. Nano-network electronic conduction in iron and nickel olivine phosphates. Nat. Mater. 3, 147-152 (2004).

20 Moriwake, H., Kuwabara, A., Fisher, C. A. J., Huang, R., Hitosugi, T., Ikuhara, Y. H., Oki, H. \& Ikuhara, Y. First-principles calculations of lithium-ion migration at a coherent grain boundary in a cathode material, $\mathrm{LiCoO}_{2}$. Adv. Mater. 25, 618-622 (2013).

21 Balke, N., Jesse, S., Morozovska, A. N., Eliseev, E., Chung, D. W., Kim, Y. Adamczy, K. L., Garcia, R. E., Dudney, N. \& Kalinin, S. V. Nanoscale mapping of ion diffusion in a lithium-ion battery cathode. Nat. Nanotech. 5, 749-754 (2010).

22 Yu, H., So, Y.-G., Kuwabara, A., Tochigi, E., Shibata, N., Kudo, T., Zhou, H. \& Ikuhara, Y. Crystalline grain interior configuration affects lithium migration kinetics in Li-rich layered oxide. Nano Lett. 16, 2907-2915 (2016).

23 Sun, Y., Zhao, L., Pan, H., Lu, X., Gu, L., Hu, Y.-S., Li, H., Armand, M., Ikuhara, Y. Chen, L. \& Huang, X. Direct atomic-scale confirmation of three-phase storage mechanism in $\mathrm{Li}_{4} \mathrm{Ti}_{5} \mathrm{O}_{12}$ anodes for room-temperature sodium-ion batteries. Nat. Commun. 4, 1870 (2013).

24 Lu, X., Zhao, L., He, X. Q., Xiao, R. J., Gu, L., Hu, Y. S., Li, H., Wang, Z. X., Duan, X. F. Chen, L. Q., Maier, J. \& Ikuhara, Y. Lithium storage in $\mathrm{Li}_{4} \mathrm{Ti}_{5} \mathrm{O}_{12}$ spinel: the full static picture from electron microscopy. Adv. Mater. 24, 3233-3238 (2012).

25 Chung, S.-Y., Bloking, J. T. \& Chiang, Y.-M. Electronically conductive phospho-olivines as lithium storage electrodes. Nat. Mater. 1, 123-128 (2002).

26 Kang, B. \& Ceder, G. Battery materials for ultrafast charging and discharging. Nature 458, 190-193 (2009).

27 Wu, X.-L., Jiang, L.-Y., Cao, F.-F., Guo, Y.-G. \& Wan, L.-J. LiFePO 4 nanoparticles embedded in a nanoporous carbon matrix: superior cathode material for electrochemical energy-storage devices. Adv. Mater. 21, 2710-2714 (2009).

28 Gibot, P., Casas-Cabanas, M., Laffont, L., Levasseur, S., Carlach, P., Hamelet, S. Tarascon, J.-M. \& Masquelier, C. Room-temperature single-phase Li insertion/extraction in nanoscale $\mathrm{Li}_{x} \mathrm{FePO}_{4}$. Nat. Mater. 7, 741-747 (2008).

29 Huang, H., Yin, S.-C. \& Nazar, L. F. Approaching theoretical capacity of LiFePO at room temperature at high rates. Electrochem. Solid State Lett. 4, A170-A172 (2001). 
30 Padhi, A. K., Nanjundaswamy, K. S. \& Goodenough, J. B. Phospho-olivines as positive-electrode materials for rechargeable lithium batteries. J. Electrochem. Soci. 144, 1188-1194 (1997).

31 Orikasa, Y., Maeda, T., Koyama, Y., Murayama, H., Fukuda, K., Tanida, H., Arai, H., Matsubara, E., Uchimoto, Y. \& Ogumi, Z. Direct observation of a metastable crystal phase of $\mathrm{Li}_{x} \mathrm{FePO}_{4}$ under electrochemical phase transition. J. Am. Chem. Soc. 135, 5497-5500 (2013)

32 Zhang, X., van Hulzen, M., Singh, D. P., Brownrigg, A., Wright, J. P., van Dijk, N. H. \& Wagemaker, M. Direct view on the phase evolution in individual $\mathrm{LiFePO}_{4}$ nanoparticles during Li-ion battery cycling. Nat. Commun. 6, 8333 (2015).

33 Liu, H., Strobridge, F. C., Borkiewicz, O. J., Wiaderek, K. M., Chapman, K. W., Chupas, P. J. \& Grey, C. P. Capturing metastable structures during high-rate cycling of $\mathrm{LiFePO}_{4}$ nanoparticle electrodes. Science 344, 1480 (2014).

34 Owen, J. \& Hector, A. Phase-transforming electrodes. Science 344, 1451-1452 (2014).

35 Nishimura, S.-I., Natsui, R. \& Yamada, A. Superstructure in the metastable intermediate-phase $\mathrm{Li}_{2 / 3} \mathrm{FePO}_{4}$ accelerating the lithium battery cathode reaction. Ang. Chem. Int. Ed. 54, 8939-8942 (2015).

36 Gu, L., Zhu, C., Li, H., Yu, Y., Li, C., Tsukimoto, S., Maier, J. \& Ikuhara, Y. Direct observation of lithium staging in partially delithiated $\mathrm{LiFePO}_{4}$ at atomic resolution. J. Am. Chem. Soc. 133, 4661-4663 (2011).

37 Suo, L., Han, W., Lu, X., Gu, L., Hu, Y.-S., Li, H., Chen, D., Chen, L., Tsukimoto, S. \& Ikuhara, Y. Highly ordered staging structural interface between $\mathrm{LiFePO}_{4}$ and $\mathrm{FePO}_{4}$. Phys. Chem. Chem. Phys. 14, 5363-5367 (2012).

38 Nishimura, S.-I., Kobayashi, G., Ohoyama, K., Kanno, R., Yashima, M. \& Yamada, A. Experimental visualization of lithium diffusion in $\mathrm{Li}_{x} \mathrm{FePO}_{4}$. Nat. Mater. 7, 707-711 (2008).

39 Sun, Y., Lu, X., Xiao, R., Li, H. \& Huang, X. Kinetically controlled lithium-staging in delithiated $\mathrm{LiFePO}_{4}$ driven by the $\mathrm{Fe}$ center mediated interlayer $\mathrm{Li}$ - $\mathrm{Li}$ interactions. Chem. Mater. 24, 4693-4703 (2012).

40 Boucher, F., Gaubicher, J., Cuisinier, M., Guyomard, D. \& Moreau, P. Elucidation of the $\mathrm{Na}_{2 / 3} \mathrm{FePO} 4$ and $\mathrm{Li}_{2 / 3} \mathrm{FePO} 4$ intermediate superstructure revealing a pseudouniform ordering in 2D. J. Am. Chem. Soc. 136, 9144-9157 (2014).

41 Malik, R., Zhou, F. \& Ceder, G. Kinetics of non-equilibrium lithium incorporation in $\mathrm{LiFePO}_{4}$. Nat. Mater. 10, 587-590 (2011).

42 Liu, X. H., Liu, Y., Kushima, A., Zhang, S., Zhu, T., Li, J. \& Huang, J. Y. In situ TEM experiments of electrochemical lithiation and delithiation of individual nanostructures. Adv. Energy Mater. 2, 722-741 (2012).

43 Huang, J. Y., Zhong, L., Wang, C. M., Sullivan, J. P., Xu, W., Zhang, L. Q., Mao, S. X., Hudak, N. S., Liu, X. H., Subramanian, A., Fan, H., Qi, L., Kushima, A. \& Li, J. In situ observation of the electrochemical lithiation of a single $\mathrm{SnO}_{2}$ nanowire electrode. Science 330, 1515-1520 (2010).

44 Zhong, L., Liu, X. H., Wang, G. F., Mao, S. X. \& Huang, J. Y. Multiple-stripe lithiation mechanism of individual $\mathrm{SnO}_{2}$ nanowires in a flooding geometry. Phys. Rev. Lett. 106, 248302 (2011)

45 Nie, A., Gan, L.-Y., Cheng, Y., Asayesh-Ardakani, H., Li, Q., Dong, C., Tao, R. Mashayek, F., Wang, H.-T., Schwingenschlögl, U., Klie, R. F. \& Yassar, R. S. Atomic scale observation of lithiation reaction front in nanoscale $\mathrm{SnO}_{2}$ materials. ACS Nano 7 , 6203-6211 (2013).

46 Wang, C.-M., Xu, W., Liu, J., Zhang, J.-G., Saraf, L. V., Arey, B. W., Choi, D., Yang, Z.-G., Xiao, J., Thevuthasan, S. \& Baer, D. R. In situ transmission electron microscopy observation of microstructure and phase evolution in a $\mathrm{SnO}_{2}$ nanowire during lithium intercalation. Nano Lett. 11, 1874-1880 (2011).

47 Wang, F., Yu, H.-C., Chen, M.-H., Wu, L., Pereira, N., Thornton, K., Van der Ven, A., Zhu, Y., Amatucci, G. G. \& Graetz, J. Tracking lithium transport and electrochemical reactions in nanoparticles. Nat. Commun. 3, 1201 (2012).

$48 \mathrm{He}$, K., Lin, F., Zhu, Y., Yu, X., Li, J., Lin, R., Nordlund, D., Weng, T.-C., Richards, R. M., Yang, X.-Q., Doeff, M. M., Stach, E. A., Mo, Y., Xin, H. L. \& Su, D. Sodiation kinetics of metal oxide conversion electrodes: a comparative study with lithiation. Nano Lett. 15, 5755-5763 (2015).

49 He, K., Xin, H. L., Zhao, K., Yu, X., Nordlund, D., Weng, T.-C., Li, J., Jiang, Y., Cadigan, C. A., Richards, R. M., Doeff, M. M., Yang, X.-Q., Stach, E. A., Li, J., Lin, F. \& Su, D. Transitions from near-surface to interior redox upon lithiation in conversion electrode materials. Nano Lett. 15, 1437-1444 (2015).

50 Chan, C. K., Peng, H., Liu, G., Mcllwrath, K., Zhang, X. F., Huggins, R. A. \& Cui, Y. High-performance lithium battery anodes using silicon nanowires. Nat. Nanotech. $\mathbf{3}$, 31-35 (2008).

51 Liu, N., Lu, Z., Zhao, J., McDowell, M. T., Lee, H.-W., Zhao, W. \& Cui, Y. A pomegranate-inspired nanoscale design for large-volume-change lithium battery anodes. Nat. Nanotech. 9, 187-192 (2014).

52 Wu, H., Chan, G., Choi, J. W., Ryu, I., Yao, Y., McDowell, M. T., Lee, S. W., Jackson, A., Yang, Y., Hu, L. \& Cui, Y. Stable cycling of double-walled silicon nanotube battery anodes through solid-electrolyte interphase control. Nat. Nanotech. 7, 310-315 (2012).

53 Liu, X. H., Wang, J. W., Huang, S., Fan, F., Huang, X., Liu, Y., Krylyuk, S., Yoo, J., Dayeh, S. A., Davydov, A. V., Mao, S. X., Picraux, S. T., Zhang, S., Li, J., Zhu, T. \& Huang, J. Y. In situ atomic-scale imaging of electrochemical lithiation in silicon. Nat. Nanotech. 7, 749-756 (2012).

54 Liu, X. H., Zheng, H., Zhong, L., Huang, S., Karki, K., Zhang, L. Q., Liu, Y., Kushima, A., Liang, W. T., Wang, J. W., Cho, J.-H., Epstein, E., Dayeh, S. A.,
Picraux, S. T., Zhu, T., Li, J., Sullivan, J. P., Cumings, J., Wang, C., Mao, S. X., Ye, Z. Z., Zhang, S. \& Huang, J. Y. Anisotropic swelling and fracture of silicon nanowires during lithiation. Nano Lett. 11, 3312-3318 (2011).

55 Yabuuchi, N., Takeuchi, M., Nakayama, M., Shiiba, H., Ogawa, M., Nakayama, K., Ohta, T., Endo, D., Ozaki, T., Inamasu, T., Sato, K. \& Komaba, S. High-capacity electrode materials for rechargeable lithium batteries: $\mathrm{Li}_{3} \mathrm{NbO}_{4}$-based system with cation-disordered rocksalt structure. Proc. Natl Acad. Sci. USA 112, 7650-7655 (2015)

56 Freire, M., Kosova, N. V., Jordy, C., Chateigner, D., Lebedev, O. I., Maignan, A. \& Pralong, V. A new active Li-Mn-O compound for high energy density Li-ion batteries. Nat. Mater. 15, 173-177 (2016).

57 Luo, K., Roberts, M. R., Hao, R., Guerrini, N., Pickup, D. M., Liu, Y.-S., Edström, K., Guo, J., Chadwick, A. V., Duda, L. C. \& Bruce, P. G. Charge-compensation in 3d-transition-metal-oxide intercalation cathodes through the generation of localized electron holes on oxygen. Nat. Chem. 8, 684-691 (2016).

58 McCalla, E., Abakumov, A. M., Saubanère, M., Foix, D., Berg, E. J., Rousse, G., Doublet, M.-L., Gonbeau, D., Novák, P., Van Tendeloo, G., Dominko, R. \& Tarascon, J.-M. Visualization of 0-0 peroxo-like dimers in high-capacity layered oxides for Li-ion batteries. Science 350, 1516-1521 (2015).

59 Seo, D.-H., Lee, J., Urban, A., Malik, R., Kang, S. \& Ceder, G. The structural and chemical origin of the oxygen redox activity in layered and cation-disordered Li-excess cathode materials. Nat. Chem. 8, 692-697 (2016)

60 Reed, J. \& Ceder, G. Role of electronic structure in the susceptibility of metastable transition-metal oxide structures to transformation. Chem. Rev. 104, 4513-4534 (2004).

61 Lee, J., Urban, A., Li, X., Su, D., Hautier, G. \& Ceder, G. Unlocking the potential of cation-disordered oxides for rechargeable lithium batteries. Science $\mathbf{3 4 3}$, 519-522 (2014).

62 Sathiya, M., Abakumov, A. M., Foix, D., Rousse, G., Ramesha, K., Saubanère, M., Doublet, M. L., Vezin, H., Laisa, C. P., Prakash, A. S., Gonbeau, D., VanTendeloo, G. \& Tarascon, J. M. Origin of voltage decay in high-capacity layered oxide electrodes. Nat. Mater. 14, 230-238 (2015).

63 Amos, C. D., Roldan, M. A., Varela, M., Goodenough, J. B. \& Ferreira, P. J. Revealing the reconstructed surface of $\mathrm{Li}\left[\mathrm{Mn}_{2}\right]_{0}$. Nano Lett. 16, 2899-2906 (2016).

64 Huang, R., Ikuhara, Y. H., Mizoguchi, T., Findlay, S. D., Kuwabara, A., Fisher, C. A. J., Moriwake, H., Oki, H., Hirayama, T. \& Ikuhara, Y. Oxygen-vacancy ordering at surfaces of lithium manganese(III,IV) oxide spinel nanoparticles. Ang. Chem. 123, 3109-3113 (2011).

65 Qian, D., Xu, B., Chi, M. \& Meng, Y. S. Uncovering the roles of oxygen vacancies in cation migration in lithium excess layered oxides. Phys. Chem. Chem. Phys. 16, 14665-14668 (2014).

66 Zandbergen, H. W., Foo, M., Xu, Q., Kumar, V. \& Cava, R. J. Sodium ion ordering in $\mathrm{Na}_{\mathrm{x}} \mathrm{CoO}_{2}$ : electron diffraction study. Phys. Rev. B 70, 024101 (2004).

67 Rodríguez-Carvajal, J., Rousse, G., Masquelier, C. \& Hervieu, M. Electronic crystallization in a lithium battery material: columnar ordering of electrons and holes in the spinel $\mathrm{LiMn}_{2} \mathrm{O}_{4}$. Phys. Rev. Lett. 81, 4660-4663 (1998).

68 Li, X., Ma, X., Su, D., Liu, L., Chisnell, R., Ong, S. P., Chen, H., Toumar, A., Idrobo, J.-C., Lei, Y., Bai, J., Wang, F., Lynn, J. W., Lee, Y. S. \& Ceder, G. Direct visualization of the Jahn-Teller effect coupled to $\mathrm{Na}$ ordering in $\mathrm{Na}_{5 / 8} \mathrm{MnO}_{2}$. Nat. Mater. 13, 586-592 (2014)

69 Lin, F., Markus, I. M., Doeff, M. M. \& Xin, H. L. Chemical and structural stability of lithium-ion battery electrode materials under electron beam. Sci. Rep. 4, 5694 (2014).

70 Lu, P., Yan, P., Romero, E., Spoerke, E. D., Zhang, J.-G. \& Wang, C.-M. Observation of electron-beam-induced phase evolution mimicking the effect of the charge-discharge cycle in Li-rich layered cathode materials used for Li ion batteries. Chem. Mater. 27, 1375-1380 (2015)

71 Phillips, P. J., Iddir, H., Abraham, D. P. \& Klie, R. F. Direct observation of the structural and electronic changes of $\mathrm{Li}_{2} \mathrm{MnO}_{3}$ during electron irradiation. Appl. Phys. Lett. 105, 113905 (2014).

72 Phillips, P. J., Bareño, J., Li, Y., Abraham, D. P. \& Klie, R. F. On the localized nature of the structural transformations of $\mathrm{Li}_{2} \mathrm{MnO}_{3}$ following electrochemical cycling. Adv. Energy Mater. 5, 1501252 (2015).

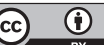

This work is licensed under a Creative Commons Attribution 4.0 International License. The images or other third party material in this article are included in the article's Creative Commons license, unless indicated otherwise in the credit line; if the material is not included under the Creative Commons license, users will need to obtain permission from the license holder to reproduce the material. To view a copy of this license, visit http:// creativecommons.org/licenses/by/4.0/

(C) The Author(s) 2017 